Article

\title{
Digital Twin for Extraction Process Design and Operation
}

\author{
Lukas Uhlenbrock ${ }^{1}$, Christoph Jensch ${ }^{1}$, Martin Tegtmeier ${ }^{2}$ and Jochen Strube ${ }^{1, *}$ \\ 1 Institute for Separation and Process Technology, Clausthal University of Technology, 38678 \\ Clausthal-Zellerfeld, Germany; uhlenbrock@itv.tu-clausthal.de (L.U.); jensch@itv.tu-clausthal.de (C.J.) \\ 2 Schaper \& Brümmer GmbH \& Co. KG, 38259 Salzgitter, Germany; martin.tegtmeier@schaper-bruemmer.de \\ * Correspondence: strube@itv.tu-clausthal.de
}

Received: 3 June 2020; Accepted: 6 July 2020; Published: 17 July 2020

check for updates

\begin{abstract}
Traditional extraction processes of natural product are widespread, especially in regulated industries. Possibilities of extraction development and manufacturing optimization in regulated industries is limited. Regulatory approvals are often based on traditional preparations of phyto-pharmaceuticals. The dependence on traditional processes can result in sub-optimal extraction parameters causing unnecessary costs and product variability. Innovative methods like Quality-by-Design (QbD), including process analytical technology (PAT), open opportunities for manufacturers to cope with regulatory demanded, narrow batch-to-batch variability. In addition, such validated process models represent perfect digital twins which could be utilized for advanced process control and life cycle analysis.
\end{abstract}

Keywords: green extraction; natural products; phytochemicals; process modeling; digital twin

\section{Introduction}

Plant-based products represent a growing market and industry is an important supplier of versatile products. The applications range from the pharmaceutical sector, food and nutrition, as well as plant protection to construction material, basic chemicals and energy resources [1-6].

The naturally occurring variability of plant material, stemming from cultivation conditions and harvest processing, requires quality assurance, especially for pharmaceutical products and other regulated industries, which are controlled by competent regulatory agencies $[7,8]$.

Traditional processes have developed over centuries. In addition, the current regulatory policy defines product quality of plant-based preparations using the traditional production processes. Most traditional herbal products are not defined by a specific active ingredient, but are comprised of a mixture of different substance classes [9,10]. In addition, traditional processes have to be established for at least 30 years to be recognized as "well established". These processes have not been designed for modern industrial process solutions and production on industrial scale [8]. The preparation of small product batches using predefined processing methods is problematic for a seamless quality assurance, as is standard for pharmaceutical preparations. Increasing value is possible by optimized usage of biomass [11,12].

To improve process robustness and increase biomass valorization, the Quality-by-Design (QbD) approach can be used to understand the impact of batch variability of the plant material on the extraction results. In previous works, the variability of different batches of plant material as well as QbD-based process design for plant-based processes is shown and researched [13-15]. Therefore, Design of Experiments (DoE) was used to identify the impact of the variation of different process parameters and to create design spaces [14]. In this work, the possibility to use a digital twin instead of experimental DoE for QbD-based process design, including an in silico DoE and the creation of design 
spaces, is shown. Furthermore, the digital twin can be used to investigate different process alternatives to assess the possible improvement on biomass valorization, value creation and productivity increase by adapting the extraction process to the behavior of the extracted components.

Model-based process design shortens time-to-market and enables comparison of many different process types for optimization. The complexity of the developed model is strongly dependent on the application of the model. Common modeling depths are shown in Figure 1. Less complex models, i.e., Black box or short cut models, are well established for early estimates of equipment dimensions during theoretical feasibility studies. The models utilized heuristic correlations and idealized assumptions regarding equilibria. The next level in detail consists of stage models, which allow for the description of equilibrium stages. Correction factors are used to describe deviations from the ideal conditions.

The distributed plug flow model (DPF) can be used to consider the effects of axial dispersion in the bulk phase and can be extended to include effects, such as pore diffusion, pore swelling, particle degradation or particle size distribution for the modeling of solid-liquid extraction processes. Further, equations for complex equilibrium conditions can be implemented.

Higher degrees of modeling depths can be found in Computational Fluid Dynamics simulations. Based on numerical solutions of the Navier-Stokes equations, fluid behavior can be simulated. Molecular dynamics can be used to describe the movement and interaction of multiple molecules, using Newton's equation for motion and interatomic potentials. Nevertheless, due to moderate flow rates, appropriate flow distribution is not the challenge in plant-based extraction processing $[13,16,17]$.



Figure 1. Overview of different modeling depths with increasing detail [18].

Higher model depth requires additional computing power and/or time. The definition of modeling depths is important to balance application of the model and modeling effort.

Model results have to be validated to confirm appropriate implementation of the theoretical approach and applicability of the model parameters required for solving the model. The accuracy and precision of a model and the possibility of experimental validation also depend on the modeling depth. The highest profit can be generated from models with comparable accuracy and precision to laboratory experiments with a validated range of parameters. In this case, a model can be used to replace experiments, saving time and resources.

For the application of solid-liquid extraction, the distributed plug flow model has proven versatile and sufficiently detailed and requires manageable computing power. The high natural variability of 
raw materials and the various properties of applied solvents may require a high level of detail, which can be introduced into the DPF model [19-21].

The required parameters of models depend on the type of model and the implemented effects. Especially, the description of fluid dynamics, phase equilibria and pore diffusion have been vital for an appropriate model of solid-liquid extraction. The modeling approach is summarized in Figure 2. This separation of the main effects influencing mass transport is a valuable tool for process understanding and can be applied to different types of plant material. The definition of model parameters and the development of a standardized model parameter determination concept allows for rapid and comparable characterization of previously unknown plant materials.



Figure 2. Model approach for solid-liquid extraction [15].

\subsection{Separation of Effects in DPF Models: Dispersion}

Dispersion allows the description of back mixing in a bulk flow, which is superimposed by diffusion. The core concept of the DPF model is shown in the following Equation (1):

$$
\frac{\partial c_{\mathrm{L}, \mathrm{i}}}{\partial t}=D_{\mathrm{ax}} \cdot \frac{\partial^{2} c_{\mathrm{L}, \mathrm{i}}}{\partial z^{2}}-\frac{u_{\mathrm{z}}}{\varepsilon} \cdot \frac{\partial c_{\mathrm{L}, \mathrm{i}}}{\partial z}-\frac{1-\varepsilon}{\varepsilon} \cdot k_{\mathrm{f}} \cdot \frac{6}{d_{\mathrm{p}}} \cdot\left[c_{\mathrm{L}, \mathrm{i}}-c_{\mathrm{P}, \mathrm{i}}\right]
$$

The first term describes the accumulation of component $i$, expressed by change of concentration $c_{\mathrm{L}}$ over time $t$. The second term represents the axial dispersion, with the axial dispersion coefficient $D_{\text {ax }}$ of component $i$ along the column coordinate $z$. Convective mass transport is expressed using the solvent velocity $u_{\mathrm{z}}$ and bed porosity $\varepsilon$. Mass transfer is specified by the mass transfer coefficient $k_{\mathrm{f}}$, the particle diameter $d_{\mathrm{p}}$ and the difference in concentration between liquid phase $c_{\mathrm{L}}$ and solid phase $c_{\mathrm{p}}$.

The dispersion coefficient is an important characteristic of extraction equipment and is important for either appropriate scale-down of production scale into laboratory scale, or efficient scale-up from lab-scale experiments. The residence time distribution, which has to be derived from equipment characterization experiments, can be used to determine the axial dispersion coefficient using the characteristic Bodenstein number.

The mean residence time, which can be derived from Equation (2), together with the variance of the mean residence time in Equation (3), can be used to calculate the Bodenstein number.

$$
\bar{t}=\frac{\sum t_{\mathrm{i}} \cdot C_{\mathrm{i}}}{\sum C_{\mathrm{i}}}
$$




$$
\sigma^{2}=\frac{\sum t_{\mathrm{i}}^{2} \cdot C_{\mathrm{i}}}{\sum C_{\mathrm{i}}}-\bar{t}^{2}
$$

The relation between axial dispersion and residence time and variance is expressed in Equation (4).

$$
\frac{\sigma^{2}}{\bar{t}^{2}}=2\left(\frac{D_{\mathrm{ax}}}{u \cdot L}\right)-2\left(\frac{D_{\mathrm{ax}}}{u \cdot L}\right)^{2}
$$

The Bodenstein number itself can be expressed by the following Equation (5):

$$
B o=\frac{u \cdot L}{D_{\mathrm{ax}}}
$$

\subsection{Separation of Effects in DPF Models: Pore Diffusion}

Pore diffusion is relevant for the description of mass transfer in porous particles. In solid-liquid extraction applications for the production of valuable products from plant material, pore diffusion is important.

$$
\varepsilon_{\mathrm{p}, \mathrm{i}} \frac{\partial c_{\mathrm{p}, \mathrm{i}}}{\partial t}+\left(1-\varepsilon_{\mathrm{p}, \mathrm{i}}\right) \frac{\partial q_{\mathrm{i}}}{\partial t}=D_{\mathrm{eff}, \mathrm{i}} \cdot\left(\frac{\partial^{2} c_{\mathrm{P}, \mathrm{i}}}{\partial r^{2}}+\frac{2}{r} \cdot \frac{\partial c_{\mathrm{P}, \mathrm{i}}}{\partial r}\right)+\frac{\partial D_{\mathrm{eff}, \mathrm{i}}}{\partial r} \cdot \frac{\partial c_{\mathrm{P}, \mathrm{i}}}{\partial r}
$$

The pore diffusion model can be derived from Fick's laws and is used to show the dependency of the loading $q$ over time $t$, radius of the plant particle $r$ and column coordinate $z$, from the effective diffusion coefficient and concentration inside the pores $c_{\mathrm{P}}$.

\subsection{Separation of Effects in DPF Models: Solid-Liquid Equilibria}

The relation between remaining load on the solid matrix and concentration in the liquid phase is described by the solid-liquid equilibrium. There are different approaches to the description of this relation [22,23]. The most common types of equilibria are shown in Figure 3 below.


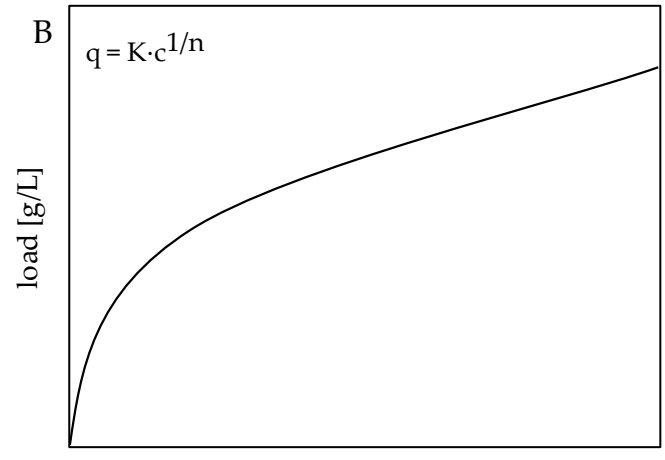

concentration $[\mathrm{g} / \mathrm{L}]$

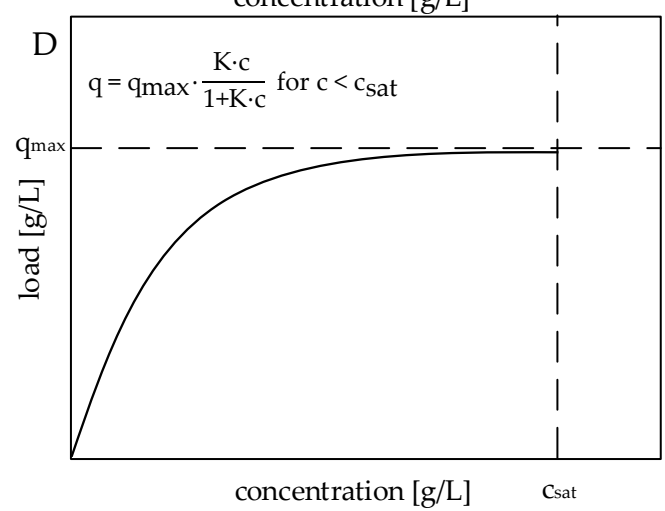

Figure 3. Solid-liquid equilibria according to Henry (A), Freundlich (B), Langmuir (C), and Langmuir with saturation concentration $(\mathbf{D})$. 
Efficient solid-liquid extraction requires high solvent utilization and is limited by the total load of target component on the matrix. The maximum load $q_{\max }$ is considered in Langmuir-Isotherm. The saturation concentration of the target component in the extraction solvent can be limiting, with high solvent utilization. This limitation occurs if an unsuitable solvent is chosen or solvent choice is limited, i.e., for regulatory reasons, and needs to be considered. The occurring mass transfer effects are dependent on different parameters, which can be assigned to three different categories, i.e., solvent, process and material parameters. The parameters, which affect solid-liquid extraction, are shown in Figure 4.


Figure 4. Relevant parameters for modeling of extraction processes.

\subsection{Quality-by-Design Approach for Process Development}

Quality-by-Design $(\mathrm{QbD})$ is a generally acknowledged and widespread tool for quality assurance in the pharmaceutical industry. The core concept of the QbD approach is the assurance of high and consistent product quality by deep understanding of the interactions of process parameters within the manufacturing process and how they affect the product quality. Within the scope of a QbD-based product development, at first, a quality target product profile (QTPP) is defined. For pharmaceuticals, this QTPP is based on pharmacokinetics, pharmacodynamics and toxicology studies. On the basis of the QTPP, critical quality attributes (CQA) are determined for the product. Applied to phytopharmaceutical extracts, this can be the purity of a target component or an overall extracted dry mass.

After the definition of CQAs, risk identification and assessment are carried out to determine the impact of different parameters within the process on product quality. A commonly used tool within risk identification is the Ishikawa method. This method is based on the cause and effect relation between quality and risk factors and is used to provide a general overview [14,24-26]. An Ishikawa diagram for the characterization of a solid-liquid extraction process is shown in Figure 5, including transfer between laboratory and production scale and common material and production parameters.

Further, risk evaluation and ranking are necessary for the development of a suitable control strategy. One popular method for risk evaluation with a higher degree of detail is the failure mode effect analysis (FMEA). All risks determined during the risk identification phase, which are summarized in the Ishikawa diagram, are rated according to their occurrence and impact. Other risk scores, e.g., risk detectability, can be used for risk evaluation and should be chosen based on the application. The risk scores of the FMEA, shown in Figure 6, need to be based on sufficient data. This data can be generated during experimental process characterization, utilizing common methods, such as statistical Design of Experiments (DoE). Additionally, validated phyisco-chemical models can be applied to demonstrate the interaction of material and process parameters and their impact on product quality. This data-based risk assessment enables the development of a design space, which allows to define an acceptable variability of different process parameters, while maintaining a defined quality profile. The development of a design space for the considered extraction process is discussed in Section 3.3.1. 




Figure 5. Ishikawa diagram for the considered solid-liquid extraction process.

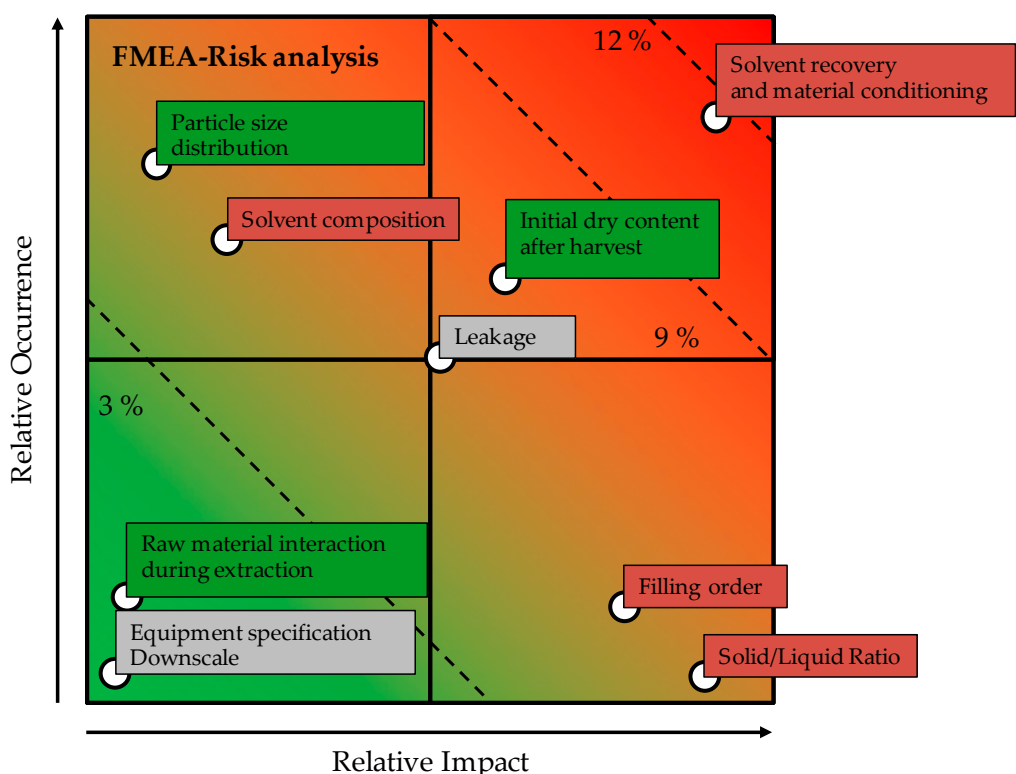

Figure 6. Qualitative failure mode effect analysis (FMEA) for the considered solid-liquid extraction process. The broken lines represent the impact on product quality based on the average value. Risk categories are colored according to the category (red = process, green = material, grey = equipment).

\subsection{Application Opportunities for Solid Liquid Extraction Models}

The presented model approach can be applied to different industrial applications of solid-liquid extraction processes. The considered model parameters for solvent and material are independent from the scale and type of the solid-liquid extractor modeled.

\subsubsection{Batch Applications}

Traditional, batch-wise maceration and temperature-elevated digestion of plant material is a common application [27]. Relevant mass transfer limitations are pore diffusion and solid-liquid equilibrium. Additional variants of this method can include the active mixing of the extraction batch, which affects mass transfer, as considered in Equation (1). Axial dispersion is less relevant for traditional maceration. 


\subsubsection{Exhaustive Flow-Through Applications}

Continuous flow of fresh solvent through a fixed bed of plant material can also be used for extraction. The continuous supply of fresh solvent allows the exhaustive extraction of the raw material, circumventing equilibrium limitations. There are several applications for exhaustive extraction, which differ mostly in the solvent properties. Percolation is used as a general term for flow-through extraction application.

With rising interest in organic solvent-free extraction methods, which abandon traditional solvents, i.e., heptane, ethyl acetate or even ethanol, water extraction has been utilized for extraction of plant material. This pressurized hot water extraction (PHWE) utilizes pressure to keep water with temperatures above $100{ }^{\circ} \mathrm{C}$ in the liquid state. The adjustment of process temperature can be used to adapt different solvent properties. Supercritical solvent extraction utilizes pressurized carbon dioxide as an extraction solvent. The main benefit of this method is the easy separation of solvent from plant material and extracted components, which can be recovered by pressure reduction. Steam treatment of plant material can also be used as an exhaustive extraction method, which is especially useful for the separation of water insoluble components, e.g., essential oils.

Both extraction methods, batch-wise and flow-through, can be adapted to include reactive conversion of target components, e.g., the degradation of hardwood for the production of small molecules, or include specialized phase separation.

\subsection{Model Validation Strategy}

The application of models for process development and optimization requires a model validation strategy. This strategy has to cover the definition of the model task, check for correct implementation of the models and include the design of a model parameter determination concept. This method has been established for different unit operations, i.e., solid-liquid extraction, liquid-liquid extraction, filtration and chromatography [12,28-31].

The separation of model effects allows for the adaption of the models to different applications and boundary conditions. One example is the implementation of systems with limited solubility of the target component in the extraction solvent. The limited solubility can be addressed by the implementation of a saturation concentration, as seen in Figure 3.

Many laboratory methods show shortcomings for a direct transfer of the developed laboratory methods into production scale. Soxhlet extraction, as one example, can be employed for exhaustive extraction, but can hardly be employed in production. Consequently, it is beneficiary to design processes based on production processes, as shown in Figure 7, which have been scaled down to laboratory scale.

Process automation should be considered for increased sample throughput and better characterization of the process. The possibilities of automated sampling and sample preparation save time and are required to maintain cost-effective process development in the lab-scale. 


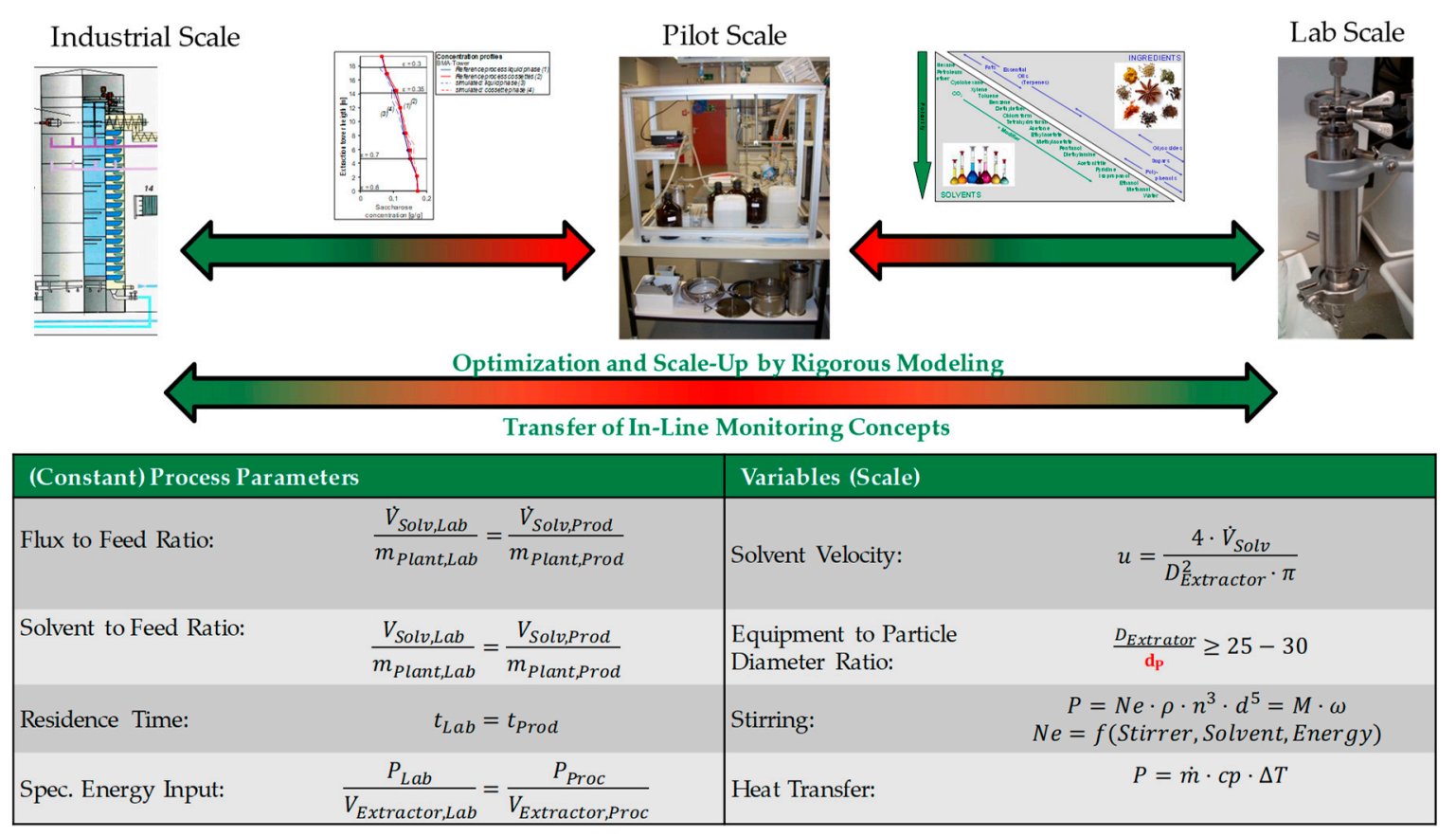

Figure 7. Scaling of laboratory equipment from production scale [20,32].

\section{Materials and Methods}

\subsection{Plant Material and Method of Extraction}

Plant material of Baptisia tinctoria (L.) Vent, Echinacea purpurea (L.) Moench, Echinacea pallida (Nutt.) Nutt. and Thuja occidentalis L. for extraction was supplied by Schaper \& Brümmer GmbH \& Co. KG, 38259 Salzgitter, Germany. As solvent, 30\% ethanol (v/v) was used for extraction. The ethanol was purchased at technical grade from VWR International GmbH, 30163 Hannover, Germany. The deionized water was taken from the in-house deionization plant.

The researched reference process consists of different extraction phases. The extraction process starts with a several-days lasting maceration phase, followed two times by a combination of solvent renewal by percolation and a one-day lasting maceration phase. The extraction process ends with a third percolation phase. The process alternatives that are shown in this work are processed exclusively in silico.

\subsection{Extraction Apparatus}

Extractions were performed in a custom-made 4-column extractor with data acquisition and process control, using Siemens S7 SPS. Solvent was pumped by a ISMATEC IPC microprocessor-controlled dosing pump with a planetary drive. Mass flow and solvent density were monitored with a Bronkhorst M15 mass flow meter. A pressure sensor from Wika monitored the solvent pressure before and after the column. The flowsheet for the extraction apparatus is shown in Figure 8.

Level detection sensors are included at the top of the extraction column. The level detection is used to detect the end of the first solvent loading step. Every extraction line includes two magnet valves. The first is located after the pump and used to redirect solvent flow back into the solvent tank. This enables the conduction of unstirred maceration experiments in the extraction column.

The sampling valve is located in front of the extract collection tank. This valve is connected to the automated sampling mechanism. In Figure 9, the automated sampling mechanism is shown. Therefore, a 3/2-way valve is installed above the sample vessel, which is opened automatically to collect extract samples at distinct times. After the sample vessel is filled, the sampling mechanism switches to the next position. 
The pump, sensors and the automated sampler are connected to a Siemens S7 1200 programmable logic controller, running a scada system (WinCC) on a windows PC. All measured data was stored in .csv data type and later retrieved from excel 2016. The automated sampling was controlled by a microcontroller (Arduino MEGA 2560R3), controlling a ACT 17HS4417 electric drive.

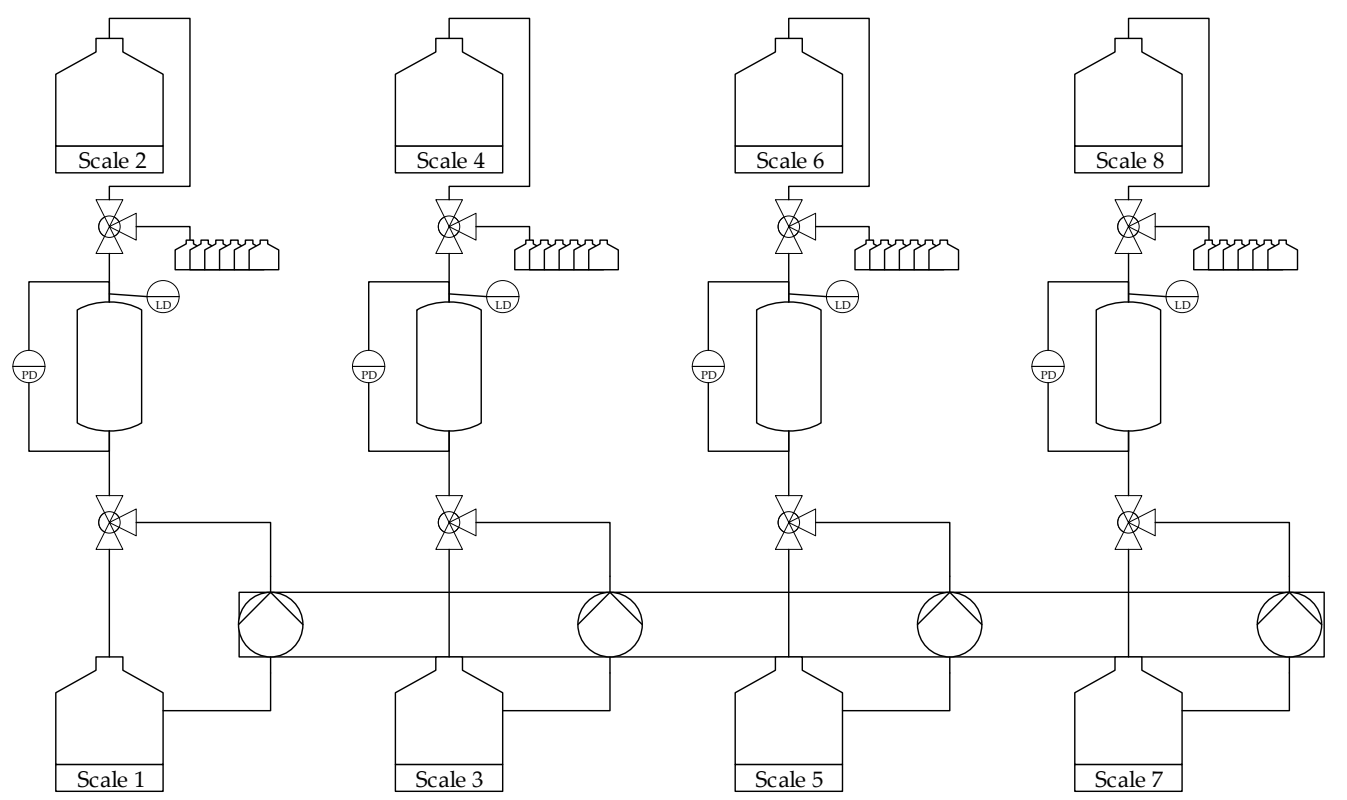

Figure 8. Multi-column extraction apparatus for automated process characterization of process sequences consisting of maceration and percolation stages.
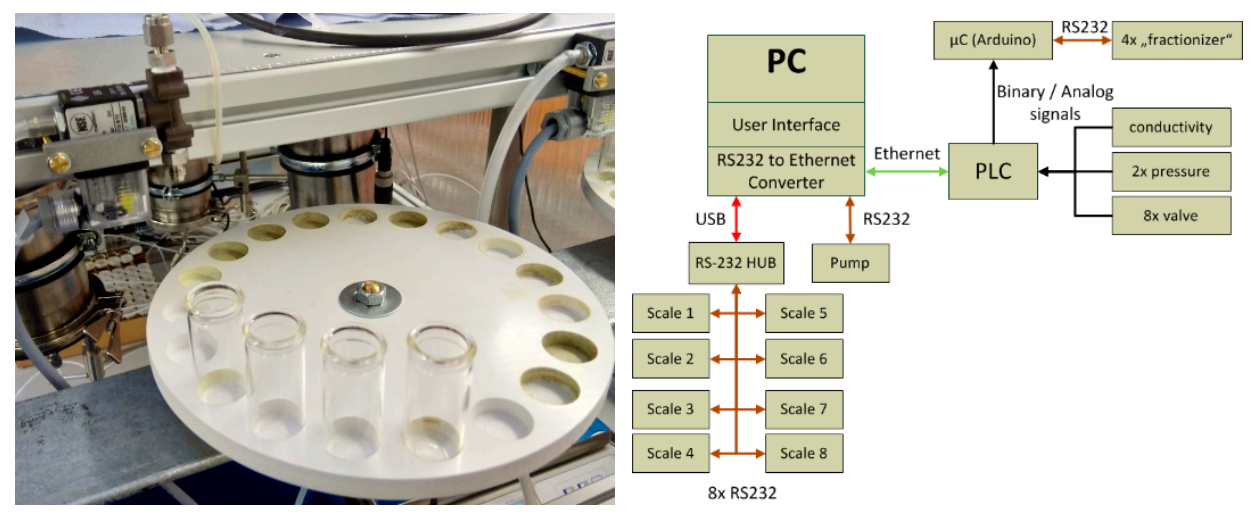

Figure 9. Automated sampling reel for sample collection.

\subsection{Dry Content Determination}

Total dry content of the extract was determined after each extraction run after the method described in the European pharmacopoeia (2.8.16 Dry residue of extracts). An amount of $2 \mathrm{~g}$ per sample was dried in glass vessels at $105^{\circ} \mathrm{C}$ for $2 \mathrm{~h}$, cooled down under dry atmosphere, and the residue was determined.

\subsection{Method of Scale Down}

A step function induced by switch of solvent from technical grade ethanol to purified water was used for the characterization of axial dispersion. The density was measured at the top of the extraction column, using a Bronkhorst M15 mass flow meter. The data for the response function was recorded with FlowDDE and Flowplot, the software from Bronkhorst, and was processed in excel. 


\section{Results}

A digital twin should be derived for all modern processes, especially those for the production of regulated, high-value products for pharmaceutical applications. A digital clone of the production process does not require the development of a completely new process, but can be performed on traditional, well-established processes.

Important for the generation of a digital twin of any given process are appropriate parameters for scale-up or scale-down for experimental characterization.

\subsection{Characterization of Fluid Dynamics}

\subsubsection{Signal of the Production Scale}

The degree of axial dispersion is dependent on the flow regime of the solvent. It can be derived from the distribution of the residence time in the extractor. This distribution can be determined from the response to a disturbance in the form of a step function of the system. Such a disturbance has been forced on the production extractor, containing a fixed bed of plant material, by a sharp change in solvent from ethanol/water to pure water. The data acquisition was stopped after 1.1 column volumes because further data points would not influence the accuracy of the data analysis. In Figure 10, the density profile during the characterization of fluid dynamics is shown. In the beginning, the whole system is filled with $20 \mathrm{vol}$ \% ethanol, with a density of $0.972 \mathrm{~g} / \mathrm{mL}$. For the characterization, water flows through the system and the density of the outgoing stream is logged.

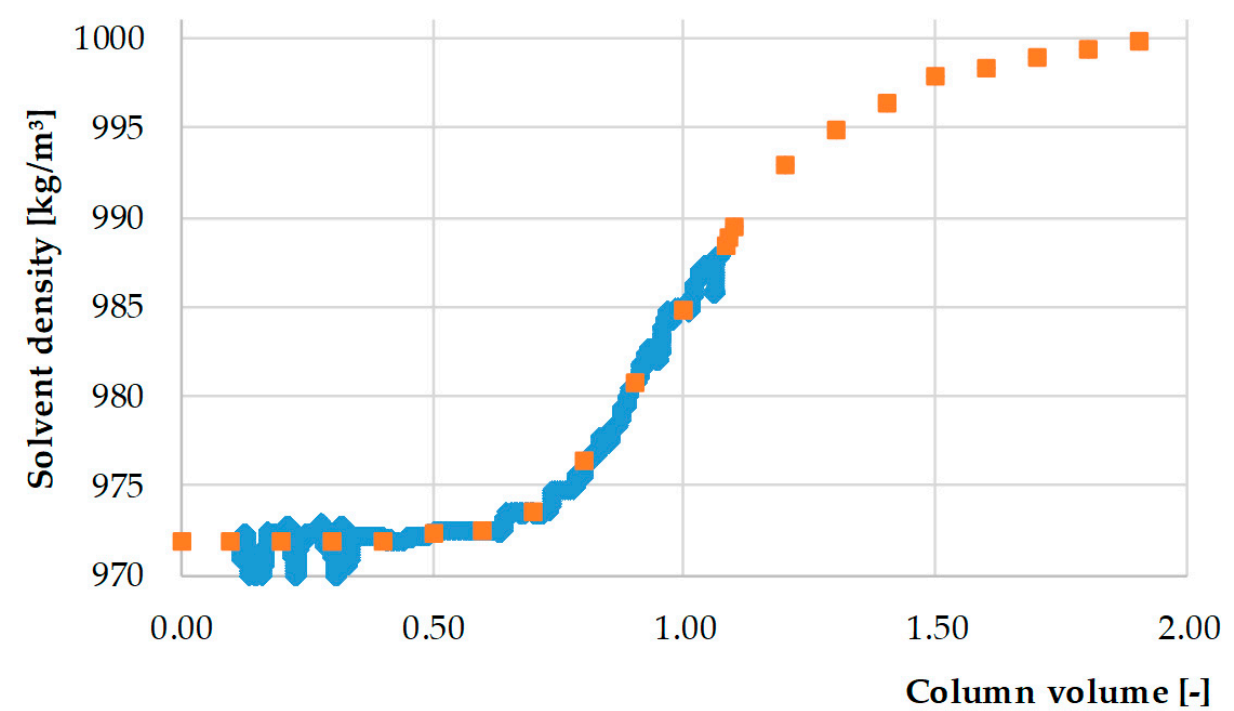

Figure 10. Step function of the production equipment.

This residence time distribution has to be matched in the laboratory scale, to guarantee adequate scale down. The characterization experiment was performed under extraction conditions. The outlier during system start up and stop of the experiment have been disregarded for the derivatization of the fit function, shown in orange.

\subsubsection{Signal of the Laboratory Scale}

The reduction of the process scale can increase the impact of the void volume of the extraction apparatus on the result of the extraction and should be minimized. The void volume can be determined by a short-cut experiment, bypassing the extraction column. The residence time distribution of the extraction apparatus, which is shown in Figure 8, is compared between input and output. To determine the impact of piping on the axial dispersion, the fluid dynamics of the laboratory set-up 
are characterized without the extraction column first. The density profile is shown in Figure 11.The experiment is carried out as explained before.



Figure 11. Determination of void volume by short-cut method.

The impact of the void volume of the extraction apparatus shows that a step signal is hardly delayed between solvent input and output. The impact of the periphery can be assumed to be insignificant for the characterization of the residence time distribution of the extraction column.

The residence time distribution of the extraction apparatus can be seen in Figure 12 for a packed column. The final comparison of the derivatives of the residence time distribution curves shows that both systems show comparable axial dispersion.

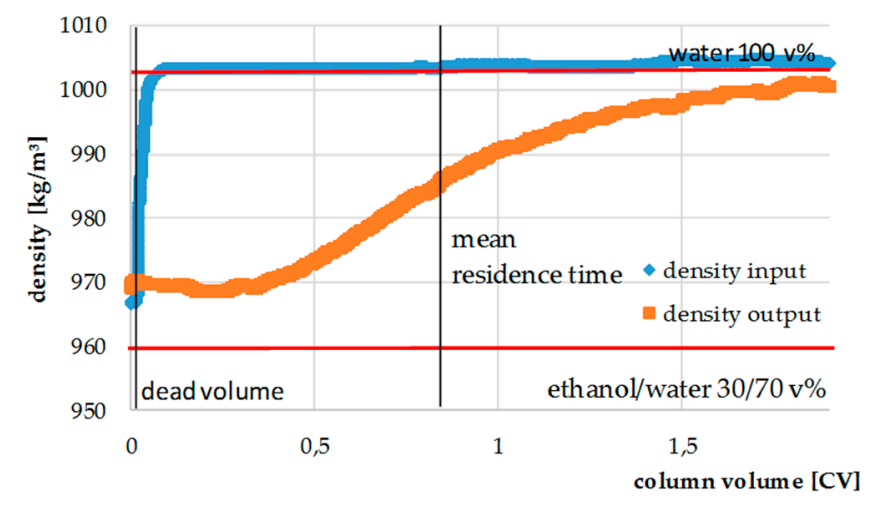

Figure 12. Residence time distribution with column and packing.

\subsubsection{Comparison of production and Laboratory Scale}

The calculation of the axial dispersion coefficient from these signal curves, according to Equations (2)-(5), confirms that the axial effects of axial dispersion can be appropriately transferred into the laboratory scale. While the laboratory equipment shows a coefficient of $0.4 \mathrm{~cm}^{2} / \mathrm{s}$, the characterization of the production equipment results in a coefficient of $0.31 \mathrm{~cm}^{2} / \mathrm{s}$. Therefore, it can be proven that the production column and periphery is appropriately scaled down. The comparison of the residence time distribution is shown in Figure 13. 


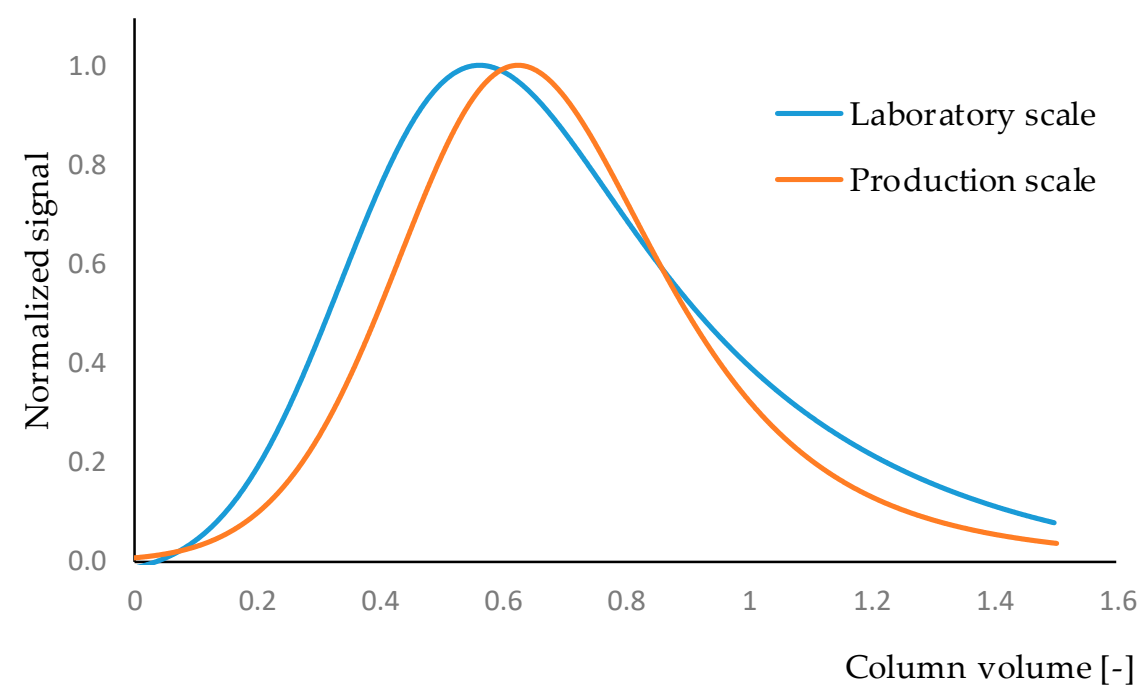

Figure 13. Direct comparison between the residence time distribution between production and laboratory scale.

\subsection{Identification of Mass Transfer Limitations from Concentration Profiles}

Regarding solid-liquid extraction of biomass, there are two major substance-specific effects which influence the efficiency of the extraction process. If a substance and its limiting effect are well known, the solid-liquid extraction process can be adapted to optimize the extraction of a specific component. The first of the mentioned limitations appears as a slow reaching of equilibrium in a maceration process or in low product concentrations in a percolation process. Those concentration profiles result from low diffusion coefficients. Therefore, the extraction is limited by mass transfer kinetics. The second type of limitation results in low concentrations in a maceration process, while in a percolation process, sufficient results can be achieved. Especially, the low concentration in the maceration process as well as the short time needed for reaching the final concentration indicate a limitation by equilibrium for that substance.

Typical concentration profiles for both types of limitation are shown in Figure 14.
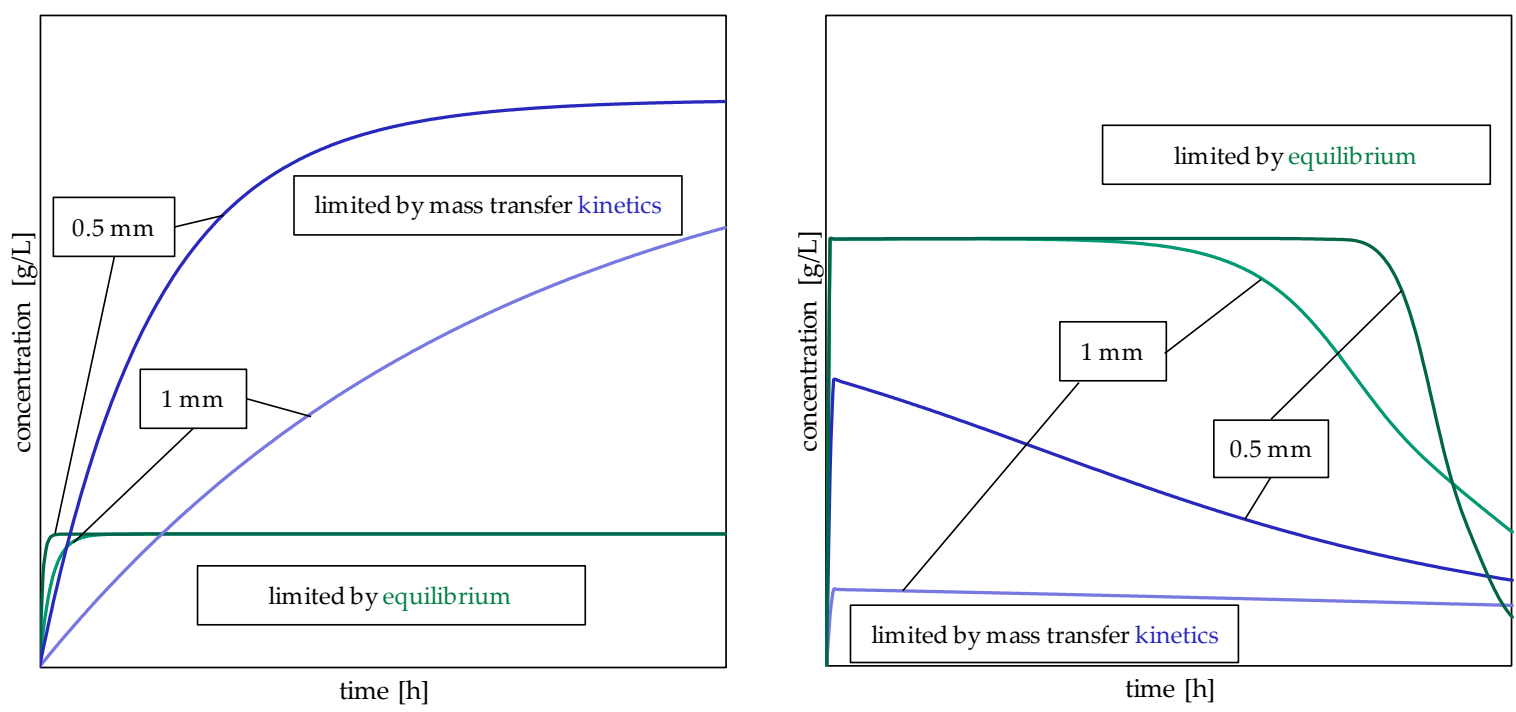

Figure 14. Concentration profiles for different limitations in a maceration process (left) and a percolation process (right). 


\subsection{Case Studies: Process Optimization for Complex, Multi-Component Mixture}

Within the scope of these case studies, a production process is taken as a reference. In the first step, the reference process is modeled and simulated. Subsequently, a DoE-based simulation study is carried out for the reference process, as it is part of a typical QbD-based process development. Therefore, a factorial design is developed, in which the mean particle diameter and the flow rate during the maceration phases are varied between five states. The following comparative model studies are carried out with an identified set of model parameters for every component. In this study, the goal was to maintain a consistent quality of the product by reaching the same standardized extracted mass for each of the four components in every process alternative. In these comparative studies, the extraction performance for each component is examined for the two basic types of extraction processes, percolation and maceration. By examining the extraction performance in maceration and percolation, the limiting mass transfer effects can be identified for each component. Afterwards, the best performing batch process is transferred into a continuous process. In the end, all processes are compared regarding the defined key parameters: space-time yield, solvent ratio and product concentration.

\subsubsection{Reference Process}

The accumulated extracted mass of the process, which is used as a reference for the following discussion of process alternatives, is shown in Figure 15. There are four different target components extracted simultaneously from four different matrices, resulting in individual extraction profiles for each component. The reference process consists of different extraction phases. The extraction process starts with a very long maceration phase, in which the system reaches its equilibrium. The loaded solvent is exchanged during a percolation phase. This combination of maceration and percolation phases is repeated three times and takes slightly longer than five days.

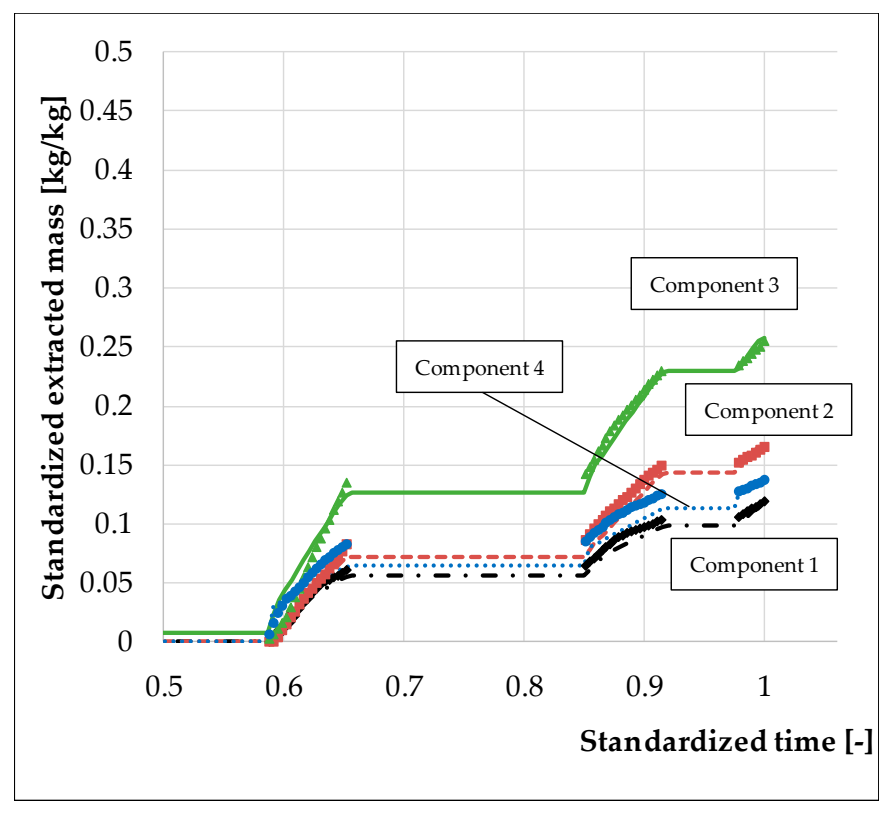

Figure 15. Profile of extracted mass for the reference process.

As in Figure 15, the extracted mass is standardized on the biomass, it can be seen that component 1 shows the strongest overall mass transfer limitation while component 3 is limited the least.

The process consists of different, long extraction phases, and consequently, the whole process lasts more than five days. Performance parameters, i.e., solvent utilization and space-time yield, are defined to reevaluate the extractability of the four components and the overall performance of the production process. 
Since design of experiments is an integral part in modern QbD-based process development and functions as the link between risk assessment and development of a design space, a factorial design of experiments with two factors and five stages is carried out in silico with the shown process model for the reference process for each component. The factors and stages are shown in Table 1. The data shown in Figure 15 function as the center point. For this process, two different product characteristics are determined for the quality of the product. The success of the extraction process is determined by the total extracted mass, which can be either expressed by the overall extracted dry mass or by the dry residue of an extract. Another criterion is the composition of the extracted dry mass. Due to the different influence of particle size and flow rate on systems, which are either limited by mass transfer kinetics or by equilibrium, both quality attributes are affected in different ways. To evaluate the impact of varying flow rates or particle sizes, the results of the DoE are shown as contour plots in Figure 16.

In this case, the dry mass content of the extract is the decisive quality criterion of the product. The range in which the variation of the dry mass content is acceptable is located between the shaded areas in every figure. For operating points with lower flow rates and larger particle sizes, the dry residue of the extract is too low, while for higher flow rates and smaller particle sizes, the dry residue of the extract achieves higher values then acceptable. A deviation of the dry mass content in both directions will affect the extracts' composition and quality due to different contents of the active pharmaceutical ingredient and components of the cell matrices, and thereby different purities of the product.

In the design spaces below, it is shown how the compositions of a 4-component extract of different limited systems are affected by variation of flow rate and particle size. The percentage of each component of the overall extracted dry mass is presented. It can be seen that for component 1 , which is strongly limited in both mass transfer effects, a combination of low flow rates and medium to larger particle sizes result in a higher percentage of component 1 dry mass within the final product. Out of these four components, component 1 is the only system which achieves a higher percentage for higher particle sizes. This fact is demonstrated by the profile in the contour plot, which stages progress from the lower left corner to the upper right, with higher percentages on the left side and lower percentages on the right side.

The reason for this is that especially, component 4 is strongly limited by mass transfer kinetics and thereby, the extraction efficiency is strongly linked to the particle size of this component. The contour lines show a contrary profile to component 1 with a higher percentage in the product for small particle sizes and low flow rates, with a high percentage on the left side of the plot and a low percentage on the right side of the plot. Depending on the operating point, the percentages of component 1 and component 4 shift into a larger percentage of one of these two components.

The two other components, 2 and 3, are not limited by mass transfer kinetics but by equilibrium, which results in a lower reliance of the extraction efficiency on the particle size. Therefore, the percentages are mostly dependent on the flow rate, which can be seen as almost orthogonal profiles on the flow rate axis in the contour plots. The percentage of component 2 and component 3 again shift in each other's direction for higher or lower flow rates. For component 2 , higher flow rates result in a higher percentage in the dry residue. This effect is contrary for component 3 , which achieves higher percentages in the dry residue for lower flow rates.

For the determination of a design space, within which borders a constant product quality can be assured, at first, the flow rate and its variation are defined. Because the flow rate is reliably controllable referred to its average fluctuation, the flow rate is set to $0.094 \pm 0.002 \mathrm{CV} / \mathrm{h}$, the center point value with two percent fluctuation in each direction. Furthermore, the acceptable fluctuation of the flow rate is limited by component 2 and component 4 on the lower end, where lower flow rates would result in a different product composition. The fluctuation to higher flow rates is limited mostly by component 3 and partly by component 2 . For this flow rate range, an acceptable mean particle diameter results for every component. The upper and lower limit for each component is set to the point for which the composition of the dry residue remains the same, while achieving the specified dry mass content in the extract between the shaded areas. This leads to a particle size diameter of $1.48 \pm 0.15 \mathrm{~mm}$ for 
component $1,1.93 \pm 0.17 \mathrm{~mm}$ for component $2,2.11 \pm 0.20 \mathrm{~mm}$ for component 3 and $1.83 \pm 0.17 \mathrm{~mm}$ for component 4 . This is equivalent to a fluctuation of about $\pm 10 \%$.

Table 1. Overview of stage values for Design of Experiments (DoE).

\begin{tabular}{ccccccc}
\hline & & Component 1 & Component 2 & Component 3 & Component 4 & \\
\hline Stage & Variation & & \multicolumn{2}{c}{ Particle Diameter (mm) } & & $\begin{array}{c}\text { Flow Rate } \\
\text { (CV/h) }\end{array}$ \\
\hline $\mathbf{2}$ & $-20 \%$ & 1.16 & 1.51 & 1.66 & 1.43 & 0.075 \\
$\mathbf{-}$ & $-10 \%$ & 1.31 & 1.70 & 1.86 & 1.61 & 0.085 \\
$\mathbf{0}$ & $\pm 0 \%$ & 1.45 & 1.89 & 2.07 & 1.79 & 0.094 \\
$\mathbf{+}$ & $+10 \%$ & 1.60 & 2.08 & 2.28 & 1.97 & 0.104 \\
$\mathbf{2 +}$ & $+20 \%$ & 1.74 & 2.27 & 2.48 & 2.15 & 0.113 \\
\hline
\end{tabular}
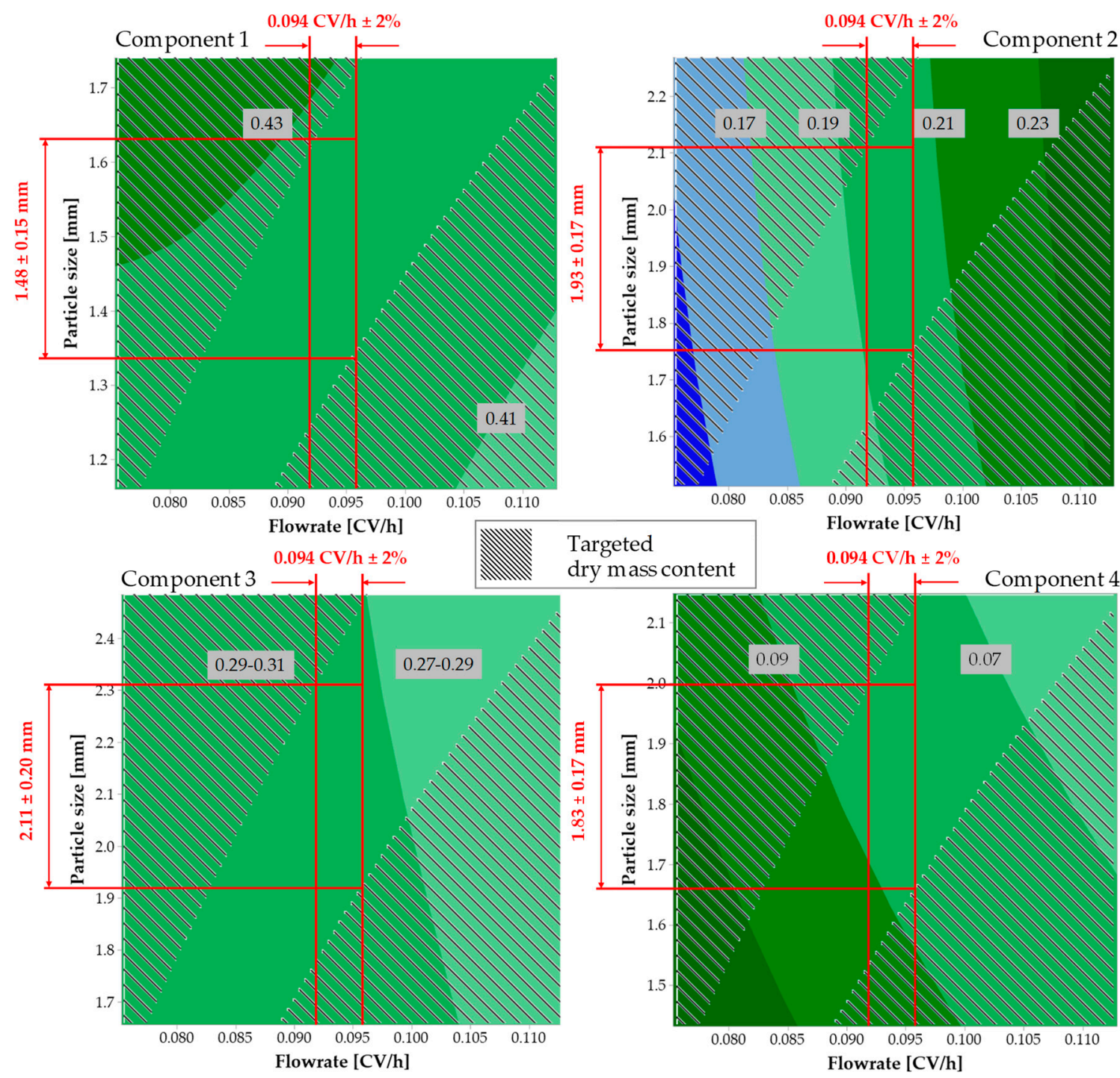

Figure 16. Design spaces for component 1-4 for varying flow rates and particle sizes.

\subsubsection{Process Alternative Non-Stop Percolation}

The first process alternative is carried out as a percolation. For this process, the extraction equipment remained the same, as well as the flow rate. Only the maceration phases between the percolation steps were cut out and the particle sizes were adjusted. 
The difference in mass transfer limitation can be mitigated by adaption of process and material parameters. The initial particle size of all target components has to be reduced by a factor of approximately 2 to mitigate the diffusion limitation, which are less obvious in the reference process, due to the long maceration phases. The exact particle sizes are shown in Table 2. Consequently, the total extraction time can be reduced from around five days to $13 \mathrm{~h}$. The extraction profiles of this alternative and the reference process are shown in Figure 17. The drawback of the percolation of diffusion-limited systems is that they can produce a higher solvent demand. Additionally, percolation of highly diffusion-limited components can cause further dilution of the extract and result in higher costs for following process steps, like the concentration by distillation.

Table 2. Overview of particle sizes in the reference process and the single step percolation.

\begin{tabular}{ccc}
\hline & \multicolumn{2}{c}{ Particle Diameter $(\mathbf{m m})$} \\
\hline & Reference & Percolation \\
\hline Component 1 & 1.45 & 0.8 \\
Component 2 & 1.89 & 1.0 \\
Component 3 & 2.07 & 1.4 \\
Component 4 & 1.79 & 1.0 \\
\hline
\end{tabular}
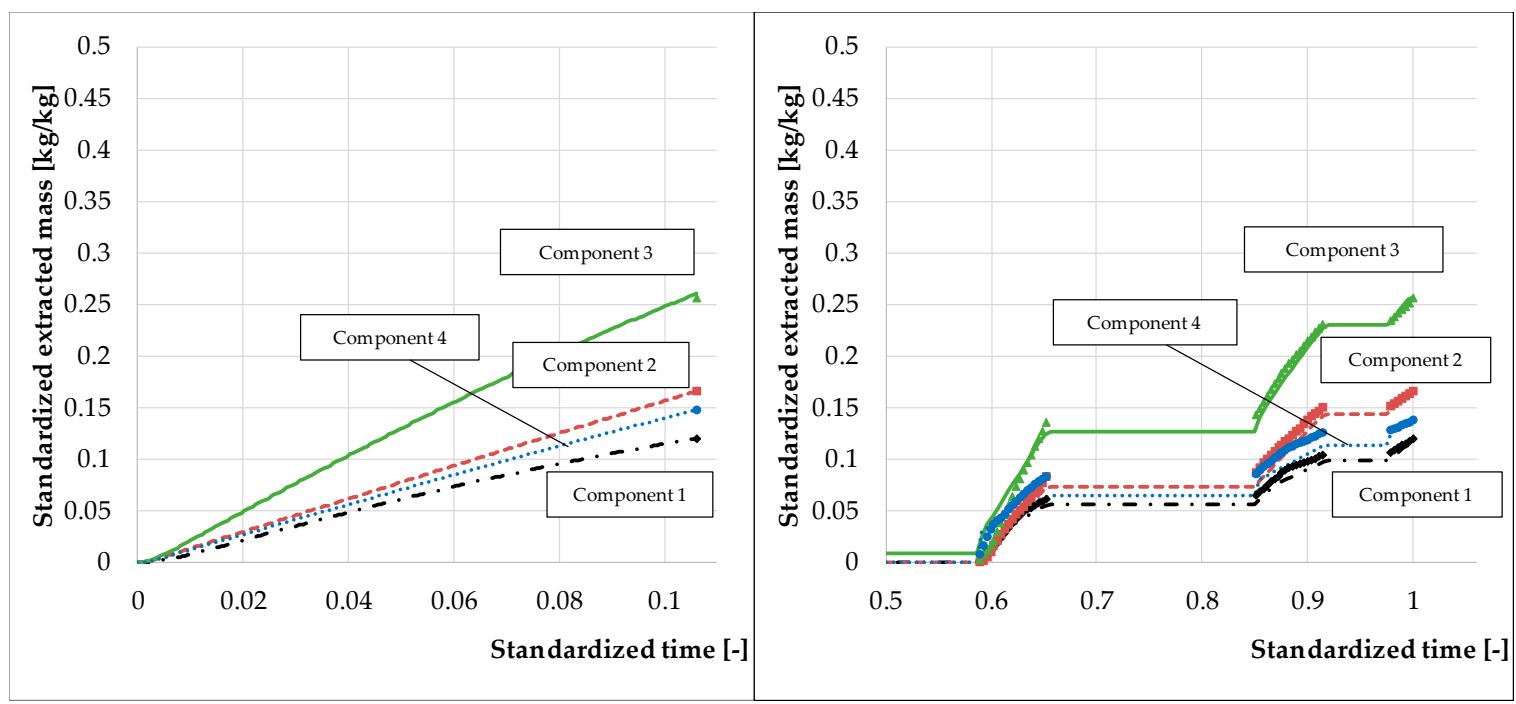

Figure 17. Comparison of the reference process (right) and a single step percolation (left) with constant product quality.

\subsubsection{Process Alternative Maceration}

As the second process alternative, a single-step maceration was simulated. The composition of the extract again has to be the same as in the reference process. For achieving this composition in an equilibrium-based process, like the maceration, the dimensions of the apparatus had to be enlarged to enable a 7-times higher solvent ratio as in the reference process. This is necessary due to the very strong equilibrium limitation of component 1 . Besides the strong equilibrium limitation, component 1 is also limited by mass transfer kinetics. Component 1 needs a particle size of $0.8 \mathrm{~mm}$ in the single step percolation, already the smallest particle size of all components, for achieving the least extracted mass per biomass. Due to the shortening of extraction time from 13 to $5 \mathrm{~h}$, an even smaller particle size of $0.05 \mathrm{~mm}$ is needed to achieve the same extraction result. Also, in Figure 18, it can be seen that the extraction profile of component 1 , despite a very high solvent ration of approximately $100 \mathrm{~kg}$ solvent per $\mathrm{kg}$ biomass, shows an equilibrium limitation. Because of the short extraction time and diffusion limitation, the particle size of component 4 also has to be reduced to $0.4 \mathrm{~mm}$. An overview of the particle sizes for each component is shown in Table 3. 


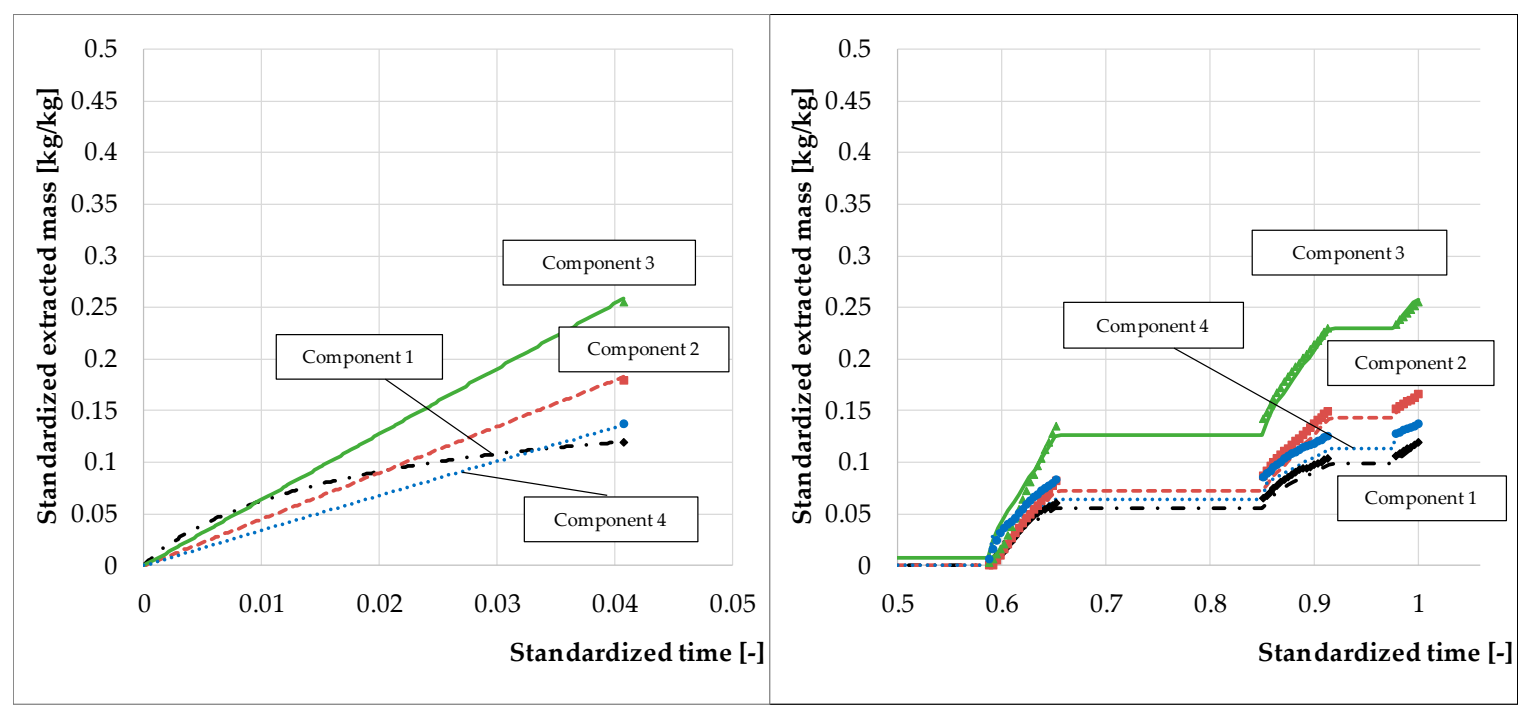

Figure 18. Comparison of the reference process (right) and a maceration (left) with constant product quality.

Table 3. Overview of particle sizes in the reference process and the maceration.

\begin{tabular}{lcc}
\hline & \multicolumn{2}{c}{ Particle Diameter $(\mathbf{m m})$} \\
\hline & Reference & Maceration \\
\hline Component 1 & 1.45 & 0.05 \\
Component 2 & 1.89 & 2.8 \\
Component 3 & 2.07 & 1.3 \\
Component 4 & 1.79 & 0.4 \\
\hline
\end{tabular}

Due to the strong equilibrium limitation of component 1 , the maceration process is not suitable for this special 4-component extraction.

\subsubsection{Small-Scale Continuous Extraction}

In the previous two model studies, the percolation turned out to be the better process alternative for extraction of the present four components. Consequently, a continuous processing concept was developed, where, originally, 15 batches per year are transferred into 220 production shifts, in which a continuous product stream is produced. Thus, the plant capacity utilization is maximized from 15 batches out of 44 possible batches per year to 220 shifts, which meets a capacity utilization of $100 \%$. Therefore, the extraction column is scaled down with a constant empty column velocity. The results of the small-scale continuous extraction are shown in Figure 19.

With a resulting shorter extraction column, the particle sizes of the biomass can also be reduced due to a generally lower pressure loss, which leads to a shortening of the extraction time down to two hours per extraction. The resulting particle sizes for each component are shown in Table 4.

To realize a continuous extraction process, a renewal of biomass has to be assured. In this case, a multicolumn concept of two columns with a suitable scheduling is provided. The scheduling is shown in Figure 20. During the two hours of extraction of the one column, the other column can be cleaned and loaded with new biomass. At the end of the extraction in the one column, the solvent stream can be switched to the freshly loaded column. During the extraction phase of the second column, the first column can be unloaded, cleaned, and loaded again. 

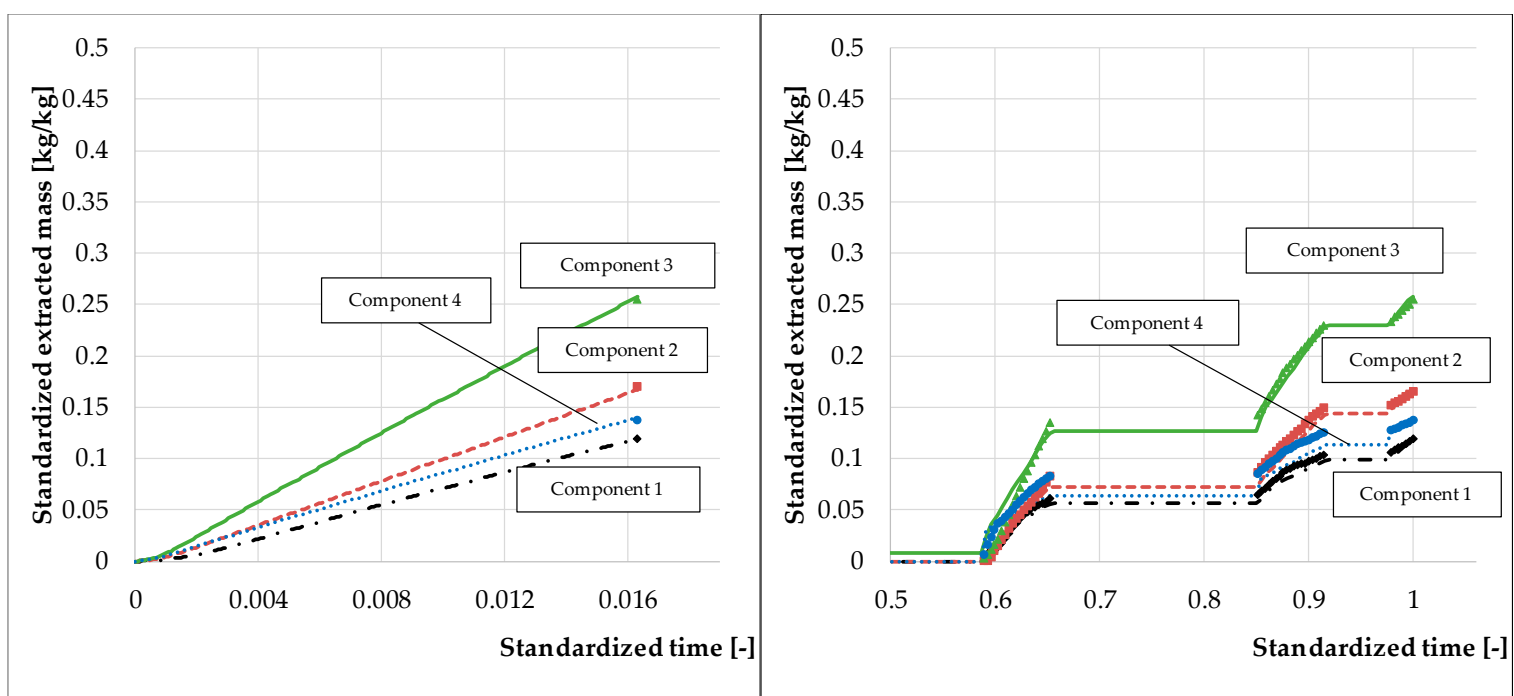

Figure 19. Comparison of the reference process (right) and a small-scale percolation (left) with constant product quality.

Table 4. Overview of particle sizes in the reference process and the small-scale continuous extraction.

\begin{tabular}{lcc}
\hline & \multicolumn{2}{c}{ Particle Diameter $(\mathbf{m m})$} \\
\hline & Reference & Small Scale \\
\hline Component 1 & 1.45 & 0.62 \\
Component 2 & 1.89 & 1.42 \\
Component 3 & 2.07 & 0.8 \\
Component 4 & 1.79 & 0.4 \\
\hline
\end{tabular}



Figure 20. Scheduling for a continuous extraction process with a two-column concept.

\subsubsection{Comparison of Key Parameters}

The solvent ratio is calculated by the used solvent mass divided by the mass of the used biomass. Therefore, the solvent ratio has to be minimized to ensure high product concentrations, low solvent costs and less solvent burdens to following downstream operations. The resulting solvent ratios as 
well as the achieved product concentrations are shown in Figure 21. The solvent ratio of the reference process, $13.7 \mathrm{~g}$ solvent per $\mathrm{g}$ biomass, could be reduced in the non-stop percolation process. Due to a reduction of the particle size for this process alternative, the overall percolation time could be reduced, resulting in a lower solvent demand at a constant flow rate. In the first examined percolation, the solvent ratio is reduced to $10.7 \mathrm{~g}$ solvent per $\mathrm{g}$ biomass, which corresponds to solvent savings of $28 \%$. With lower solvent consumption by extracting the same overall amount of target components, the product concentration rises. In this case, the product concentration rose from $1.4 \%$ to $1.8 \%$, which is an increase of $28 \%$ likewise.
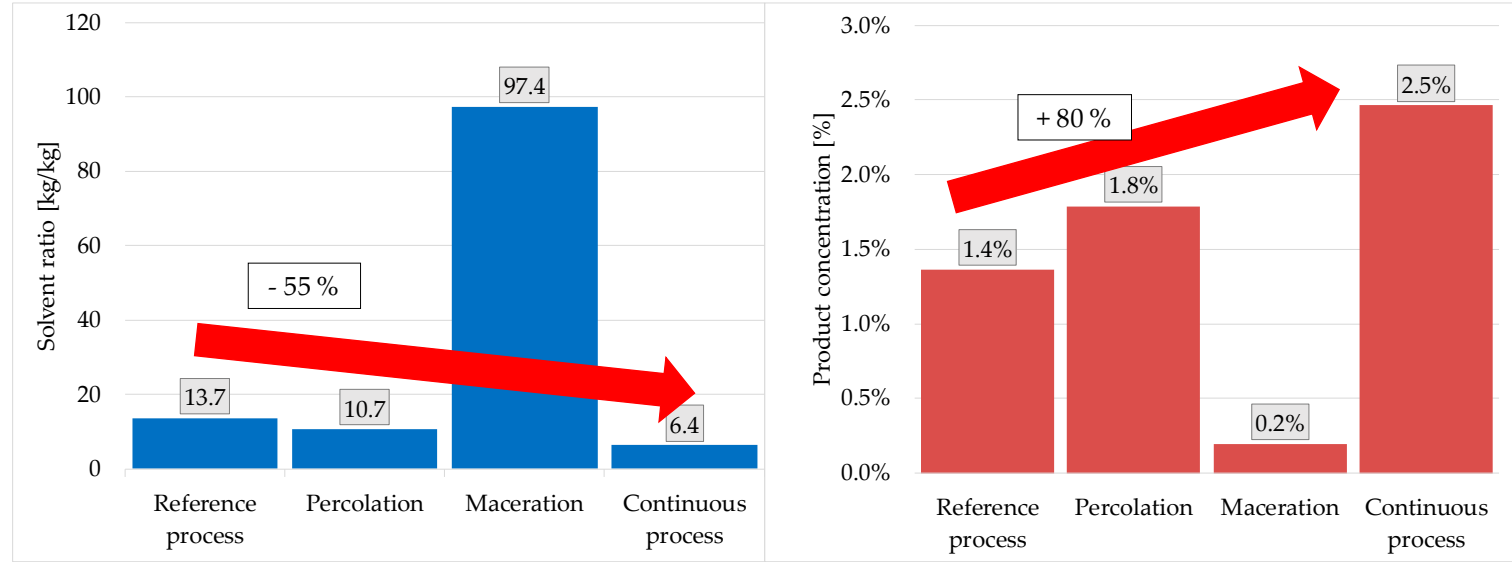

Figure 21. Comparison of the solvent ratio (left) and product concentration (right) for the examined process alternatives.

Another important parameter for the evaluation of whether the performance of a process is sufficient or not is the space-time yield. The space-time yield shows off how much product mass is produced per volume of equipment and processing time in $\mathrm{kg} / \mathrm{m}^{3} \cdot \mathrm{h}$. The space-time yields of the presented process alternatives are shown in Figure 22.



Figure 22. Comparison of the space-time yield for the examined process alternatives.

It can be seen that the reference process only achieves a low space-time yield of $0.3 \mathrm{~kg} / \mathrm{m}^{3} \cdot \mathrm{h}$. In this case, the very long overall process time due to the long maceration phases is the main reason that lowers the space-time yield. By shortening the process time in the single step percolation process, while both other influencing parameters, product mass and extractor volume, remain the same, the space-time yield rises 8.6 times, to $2.6 \mathrm{~kg} / \mathrm{m}^{3} \cdot \mathrm{h}$. The insufficient overall performance of the maceration process, as already shown before, can again be seen in the space-time yield. The maceration process achieves a space-time yield of $0.4 \mathrm{~kg} / \mathrm{m}^{3} \cdot \mathrm{h}$, which complies more or less with the space-time yield of 
the reference process. Even by reducing the overall process time in the maceration process, the need of the seven-fold solvent mass, as needed in the reference process, and therefore the seven-fold extractor volume, compensates the positive effect of a shorter process time. As already seen in the comparisons before, the small-scale continuous percolation process has the best performance, regarding space-time yield, too. Regarding the reference process, the small-scale continuous process achieves the 56-fold space-time yield with a value of $16.8 \mathrm{~kg} / \mathrm{m}^{3} \cdot \mathrm{h}$. This high space-time yield is not only caused by a very short process time, but also due to the reduction of extractor volume, which can be achieved by increasing the plant capacity utilization and continuous processing.

\section{Discussion}

This research shows the possibility to display complex extraction processes with different extraction phases of an even more complex system of four different types of plant material within a digital twin modeling approach. With a validated model in the form of a digital twin, it is feasible to create different extraction processes within the model itself to achieve a fast overview over the characteristics of the different components and their extraction behavior. With the knowledge of the different mass transfer mechanisms and the identification of the specific limitations of the different components, a best performing process alternative can be designed. Therefore, the digital twin must be able to handle all different mass transfer phenomena to reach generally valid predictions on the basis of substance data, e.g., diffusion coefficient or equilibrium behavior. This does not only offer the possibility to do further research on existing processes, but also to create a whole new process for an available component with less experimental effort. To do further and deeper research on existing processes, it is crucial that the equipment used for the production can be scaled down properly. Within the scope of this work, a successful method to scale down a production extractor into laboratory scale was also described and elaborated.

The case study also shows how the different limitations in the mass transfer, mass transfer kinetics and equilibrium affect the two base types of extraction, percolation and maceration. It can be seen that components with a strong equilibrium limitation, like component 1 , are not sufficiently extractable in a maceration process. The only possibility to overcome a strong equilibrium limitation in a maceration process is by increasing the applied solvent mass, which leads to a less economic and ecological process. The considered percolation, however, shows that components with a limitation in mass transfer kinetics, like component 4 , are only performing sufficiently if the particle size is decreased. Taking the pressure loss into account, this method of decreasing the particle size to overcome this limitation has a natural lower limit below which the process is not applicable anymore. This leads to the overview shown in Figure 23. In this overview, the qualitative potential of different extraction methods to overcome the two mentioned mass transfer limitations are shown. Generally, it can be stated that most extraction methods perform well in the lower left quadrant, where the components show neither a strong equilibrium limitation nor a strong limitation of mass transfer kinetics. In this quadrant, maceration, as well as percolation, deliver sufficient extraction results. The higher the equilibrium limitation, shown on the $y$-axis, the more preferable the application of percolation, whereas the higher the limitation of mass transfer kinetics, the more preferable the application of maceration. For strong equilibrium-limited components, it could be favorable to run multiple shorter columns to overcome the reaching of equilibrium state within the extraction column. It is also shown that with rising limitation by mass transfer kinetics, a reduction of particle size should be considered, e.g., to shorten process times in maceration. Another positive effect in overcoming a strong limitation by mass transfer kinetics can be achieved by raising the temperature of the extraction medium. A prominent example for this extraction technique is the pressurized hot water extraction (PHWE), which can be realized either as percolation or maceration [21,28,33-35]. Furthermore, different plant systems that were characterized are shown in Figure 23. 


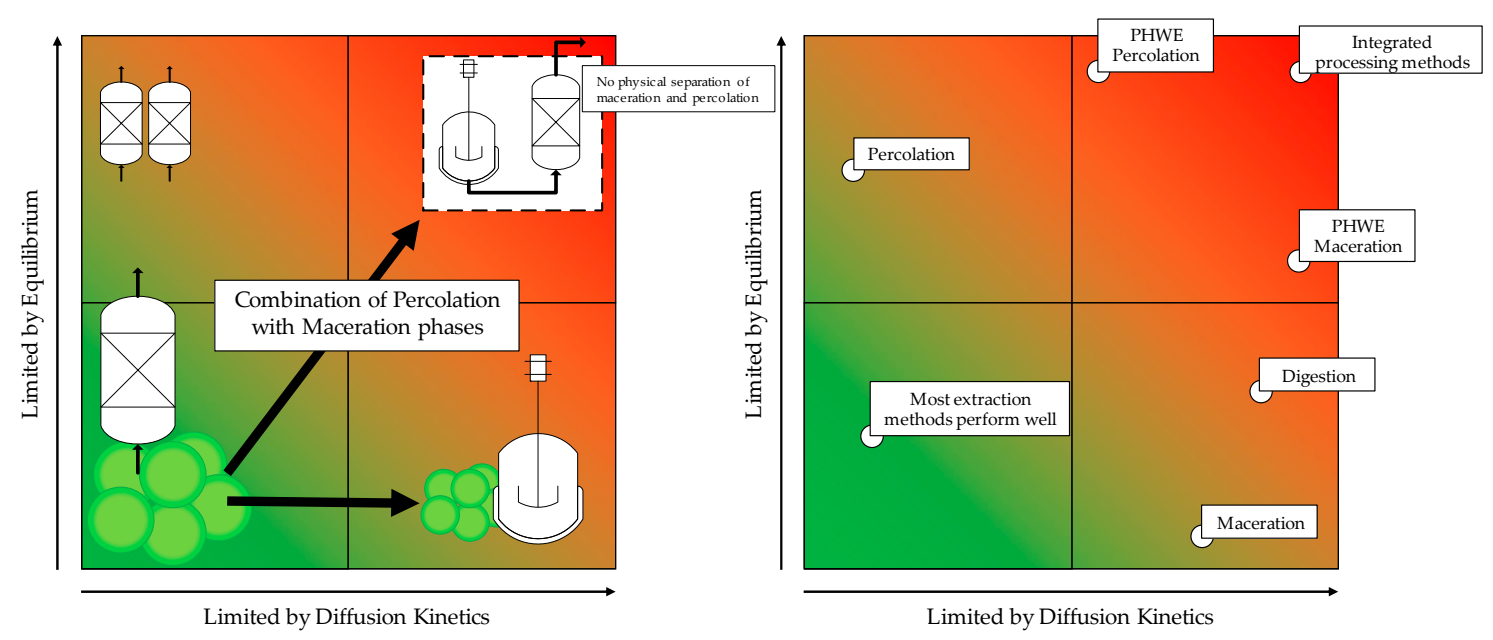

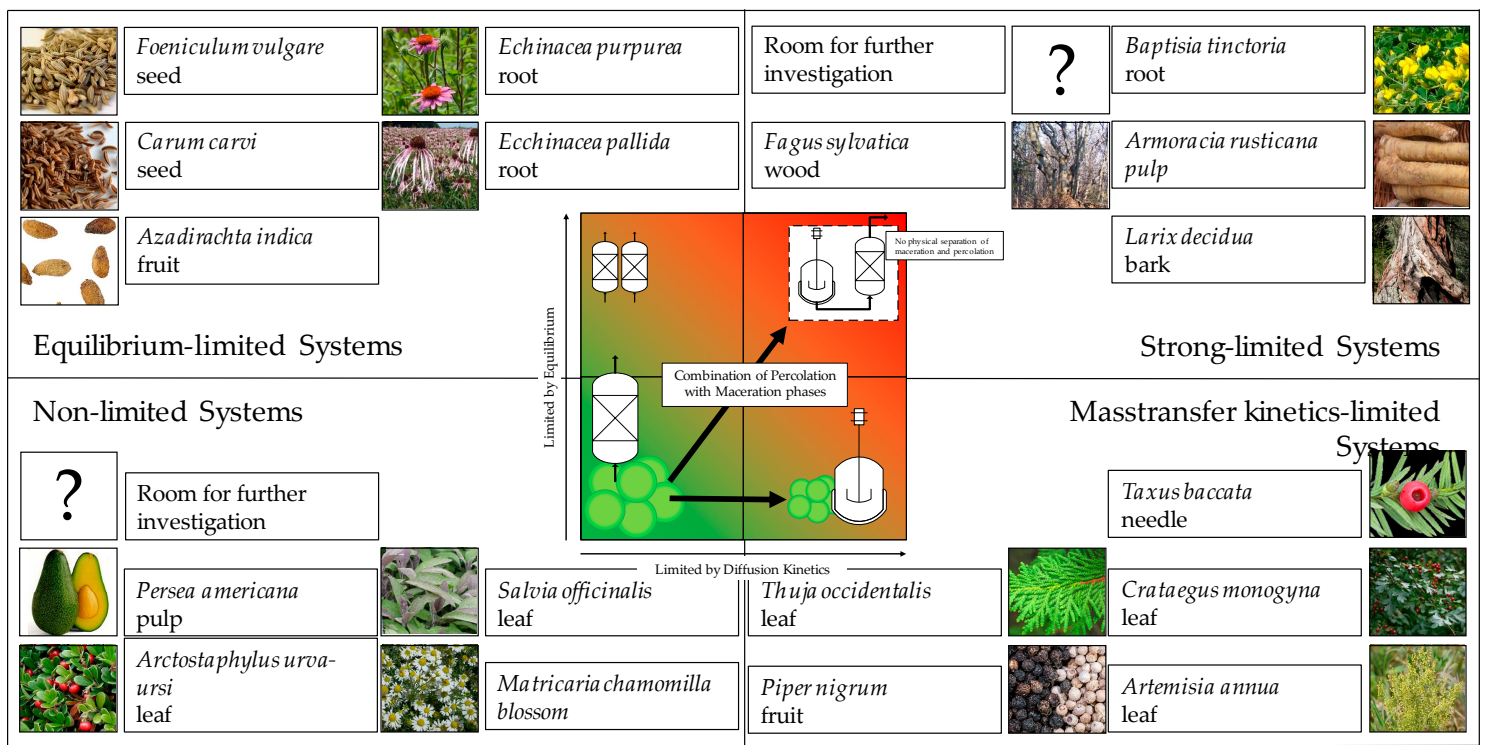

Figure 23. Potential of different extraction methods in handling two basic mass transfer limitations and overview of different characterized plant systems.

Besides the basic types of extraction, maceration and percolation, and modifications of those extraction techniques, e.g., by adjusting temperatures, many different extraction techniques are applied in different sectors of the biomass processing industries. For example, for the purification of opiates from plant particles [36,37], continuous extraction and purification techniques are especially beneficial for large-scale industrial applications [38-43]. Table 5 provides an overview of the most common extractor types for continuous processing in plant-based industries. 
Table 5. Overview of different apparatuses for continuous processing of biomass [32].

\begin{tabular}{|c|c|c|c|c|c|c|c|}
\hline & Extractors & Capacity $[t / d]$ & Yield [-] & $\begin{array}{c}\text { Solid-liquid } \\
\text { Ratio [-] }\end{array}$ & $\begin{array}{l}\text { Resi-dence } \\
\text { Time [min] }\end{array}$ & $\begin{array}{l}\text { Equilib-rium } \\
\text { Stages [-] }\end{array}$ & $\begin{array}{c}\text { Corn } \\
\text { Size }[\mathrm{mm}]\end{array}$ \\
\hline $\begin{array}{l}\text { BMA, } \\
\text { Germany }\end{array}$ & $\begin{array}{l}\text { BMA } \\
\text { tower } \\
\text { extractor }\end{array}$ & $4000-17,000$ & 99 & $3-5$ & $90-150$ & $\mathrm{n} / \mathrm{a}$ & $5-100$ \\
\hline \multirow{3}{*}{$\begin{array}{l}\text { Crown Iron Works, } \\
\text { USA }\end{array}$} & $\begin{array}{c}\text { Model III }{ }^{\mathrm{TM}} \\
\text { Percolation type }\end{array}$ & Up to 12,000 & $80-99$ & $0.8-8$ & $30-180$ & $\mathrm{n} / \mathrm{a}$ & $1-20$ \\
\hline & $\begin{array}{c}\text { Model IV }{ }^{\mathrm{TM}} \\
\text { Immersion type }\end{array}$ & Up to 800 & $80-99$ & $0.8-8$ & $30-300$ & $\mathrm{n} / \mathrm{a}$ & $1-20$ \\
\hline & $\begin{array}{l}\text { Model } \mathrm{V}^{\mathrm{TM}} \text { (speciality } \\
\text { materials) Percolation } \\
\text { type }\end{array}$ & Up to 800 & $80-99$ & $0.8-8$ & $30-300$ & $\mathrm{n} / \mathrm{a}$ & $1-20$ \\
\hline \multirow{2}{*}{$\begin{array}{l}\text { De Smet, } \\
\text { Belgium }\end{array}$} & $\begin{array}{l}\mathrm{LM}^{\mathrm{TM}} \\
\text { extractor }\end{array}$ & $500-5000$ & 99 & approx. 1 & $60-120$ & $5-10$ & $0.3-15$ \\
\hline & Reflex $^{\mathrm{TM}}$ extractor & $500-12,000$ & 99 & approx. 1 & $60-120$ & $5-10$ & $0.3-15$ \\
\hline GEA Niro, Denmark & Contex $^{\mathrm{TM}}$ extractor & $12-24$ & $>90$ & approx. 6 & $30-120$ & $3-5$ & $0.9-50$ \\
\hline $\begin{array}{l}\text { Harburg-Freuden-berger, } \\
\text { Germany }\end{array}$ & $\begin{array}{l}\text { Carousel }^{\mathrm{TM}} \\
\text { extractor }\end{array}$ & $50-5,000$ & $92-98$ & $0.85-1$ & $30-90$ & $\mathrm{n} / \mathrm{a}$ & $\mathrm{n} / \mathrm{a}$ \\
\hline Lurgi, Germany & Sliding Cell ${ }^{\mathrm{TM}}$ extractor & $100-5,000$ & 98-99 & $n / a$ & $\mathrm{n} / \mathrm{a}$ & $8-12$ & $0.5-20$ \\
\hline
\end{tabular}


Even though the extraction techniques, which are applied in these different extractor types, seem different from the two base types, percolation and maceration, the extractor types shown above can be transferred into equivalent flowsheets. These equivalent flowsheets consist again of a connection of multiple percolations, or percolation and maceration phases. An example for an equivalent flowsheet for the carousel extractor is shown in Figure 24. This extraction process consists of $n$ percolation columns with n-2 effective extraction, respectively percolation, phases as well as one loading step and one unloading step of the plant material. By transferring these complex extraction apparatuses into a specific equivalent flowsheet, a separation of effects and therefore a modeling of this specific process becomes possible.

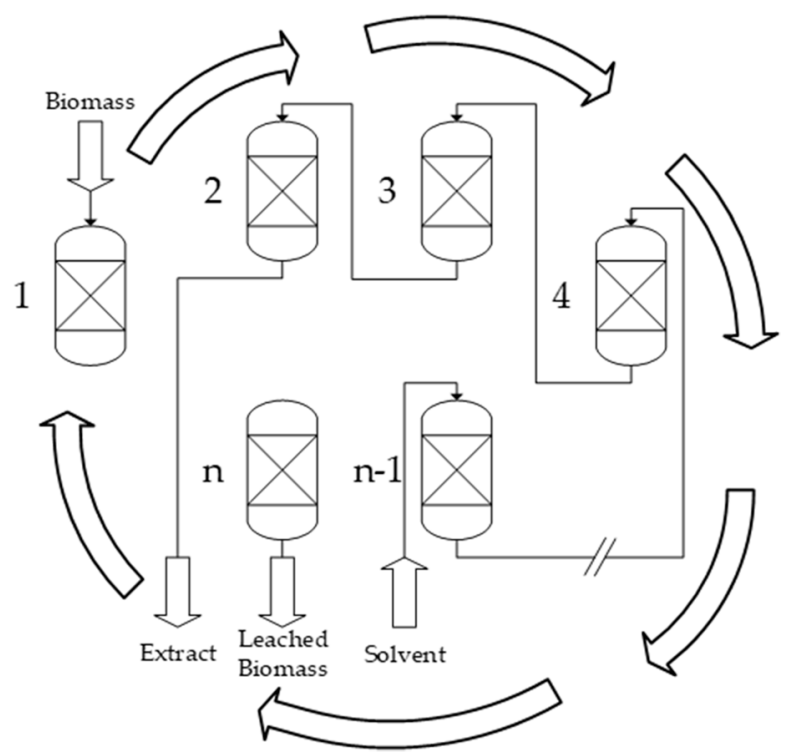

Figure 24. Equivalent flowsheet for a carousel extractor.

\section{Conclusions}

This work shows the possibility to create a digital twin based on a validated physico-chemical model for both complex component systems with multiple limitations and complex processes with multiple different extraction phases. The required model parameters can be determined with a lab-scale plant, which is successfully down-scaled from the production scale. On the basis of the digital twin, the components can be categorized, and their extraction behavior can be observed for different extraction techniques. Moreover, the possibility to carry out a large amount of simulations or different operating points can be used to establish a design space for a complex extraction process. Furthermore, the successfully developed design spaces show the possible application of digital twins within a QbD-based process development. Additionally, the separation of different mass transfer effects allows the modeling of complex, continuous extraction methods by developing an equivalent flowsheet by dividing the process into maceration and percolation phases.

Author Contributions: Conceptualization, J.S. and M.T.; writing-original draft preparation, L.U. and C.J.; visualization, C.J.; supervision, J.S. All authors have read and agreed to the published version of the manuscript.

Funding: The authors would like to thank the Bundesministerium für Wirtschaft und Energie (BMWi), especially M. Gahr (Projektträger FZ Jülich, FKZ: 03ET1365A).

Acknowledgments: The authors gratefully acknowledge the support of Schaper \& Brümmer GmbH \& Co. KG.

Conflicts of Interest: The authors declare no conflict of interest. 


\section{Nomenclature}

\section{Latin Symbols}

A

c

$d$

$D_{\mathrm{ax}}$

$D_{\text {eff }}$

K

$k_{\mathrm{f}}$

$L$

m

$q$

$r$

$t$

T

u

V

$z$

Greek Symbols

$\varepsilon$

$\rho$

$\sigma^{2}$
Area

Concentration

Diameter

Axial dispersion coefficient

Effective diffusion coefficient

Equilibrium constant

Mass transfer coefficient

Length

Mass

Loading

Radius

Time

Temperature

Empty pipe velocity

Volume

Coordinate

Porosity

Density

Variance $\mathrm{cm}^{2}$

$\mathrm{g} / \mathrm{L}$

$\mathrm{cm}$

$\mathrm{m}^{2} / \mathrm{s}$

$\mathrm{m}^{2} / \mathrm{s}$

$-$

$\mathrm{cm}$

$\mathrm{g}$

$\mathrm{g} / \mathrm{L}$

$\mathrm{cm}$

$\min$

${ }^{\circ} \mathrm{C}$

$\mathrm{cm} / \mathrm{min}$

$\mathrm{cm}^{3}$

$\mathrm{cm}$

$\mathrm{g} / \mathrm{L}$

Abbreviations and Indices

$\begin{array}{ll}\text { CQA } & \text { Critical Quality Attribute } \\ \text { DoE } & \text { Design of Experiments } \\ \text { DPF } & \text { Distributed plug flow } \\ \text { eq } & \text { Index: state of equilibrium } \\ \text { FMEA } & \text { Failure Mode and Effect Analysis } \\ \text { i } & \text { Index: Component i } \\ 1 & \text { Index: in liquid phase } \\ \text { max } & \text { maximum } \\ \text { p } & \text { Index: in particle } \\ \text { PAT } & \text { Process analytical technology } \\ \text { PHWE } & \text { Pressurized Hot Water Extraction } \\ \text { QbD } & \text { Quality-by-Design } \\ \text { QTPP } & \text { Quality Target Product Profile } \\ \text { sat } & \text { Index: saturation } \\ \text { SLE } & \text { Solid-Liquid Extraction } \\ \text { STY } & \text { Space-time yield }\end{array}$

\section{References}

1. Borges, A.; Abreu, A.C.; Dias, C.; Saavedra, M.J.; Borges, F.; Simões, M. New Perspectives on the Use of Phytochemicals as an Emergent Strategy to Control Bacterial Infections Including Biofilms. Molecules 2016, 21, 877. [CrossRef] [PubMed]

2. Leonel, M.; Sarmento, S.B.; Cereda, M.P. New starches for the food industry: Curcuma longa and Curcuma zedoaria. Carbohydr. Polym. 2003, 54, 385-388. [CrossRef]

3. Kleeberg, H. Method for the Production of Storage Stable Azadirachtin from Seed Kernels of the Neem Tree. U.S. Patent 5,695,763, 9 December 1997.

4. Fraunhofer-Projektgruppe für Wertstoffkreisläufe und Ressourcenstrategie. Positionspapier zu Bioplastik. 2018. Available online: https:/www.iwks.fraunhofer.de/de/presse-und-medien/pressemeldungen-2018/ positionspapier-zu-bioplastik.html (accessed on 3 December 2018).

5. DECHEMA. Fortschrittliche Alternative Flüssig Brenn- und Kraftstoffe: Für Klimaschutz im Globalen Rohstoffwandel; DECHEMA e.V.: Frankfurt, Germany, 2017. 
6. Bundesministerium für Bildung und Forschung. Nationale Forschungsstrategie BioÖkonomie 2030; Herausgeber Bundesministerium für Bildung und Forschung (BMBF) Referat Bioökonomie: Bonn/Berlin, Germany, 2010.

7. Community Procedures for the Authorisation and Supervision of Medicinal Products for Human and Veterinary Use and Establishing a European Medicines Agency; (EC) No 726/2004; European Parliament: Brussels, Belgium, 2004.

8. Directive 2004/24/EC Amending, as Regards Traditional herbal Medicinal Products, Directive 2001/83/EC on the Community Code Relating to Medicinal Products for Human Use; Directive 2004/24/EC; European Parliament: Brussels, Belgium, 2004.

9. European Medicines Agency. Assessment Report on Echinacea Purpurea L Moench Radix; Committee on Herbal Medicinal Products (HMPC): London, UK, 2017.

10. Heinrich, M. Teedrogen und Phytopharmaka. Ein Handbuch für die Praxis auf wissenschaftlicher Grundlage [Herbal Medicines and Phytomedicines. A Science Based Manual for the Practice]. J. Ethnopharmacol. 2003, 84, 121-122. [CrossRef]

11. Uhlenbrock, L.; Ditz, R.; Strube, J. Process Engineering Accelerating an Economic Industrialization Towards a Bio-Based World. Molecules 2019, 24, 1853. [CrossRef] [PubMed]

12. Sixt, M.; Schmidt, A.; Mestmäcker, F.; Huter, M.J.; Uhlenbrock, L.; Strube, J. Systematic and Model-Assisted Process Design for the Extraction and Purification of Artemisinin from Artemisia annua L.-Part I: Conceptual Process Design and Cost Estimation. Processes 2018, 6, 161. [CrossRef]

13. Sixt, M.; Strube, J. Systematic Design and Evaluation of an Extraction Process for Traditionally Used Herbal Medicine on the Example of Hawthorn (Crataegus monogyna JACQ.). Processes 2018, 6, 73. [CrossRef]

14. Uhlenbrock, L.; Sixt, M.; Strube, J. Quality-by-Design (QbD) process evaluation for phytopharmaceuticals on the example of 10-deacetylbaccatin III from yew. Resour. Technol. 2017, 3, 137-143. [CrossRef]

15. Sixt, M.; Uhlenbrock, L.; Strube, J. Toward a Distinct and Quantitative Validation Method for Predictive Process Modelling-On the Example of Solid-Liquid Extraction Processes of Complex Plant Extracts. Processes 2018, 6, 66. [CrossRef]

16. Sixt, M.; Koudous, I.; Strube, J. Process design for integration of extraction, purification and formulation with alternative solvent concepts. C. R. Chim. 2016, 19, 733-748. [CrossRef]

17. Both, S. Systematische Verfahrensentwicklung für Pflanzlich Basierte Produkte im Regulatorischen Umfeld; Shaker: Aachen, Germany, 2015; ISBN 9783844037272.

18. Roth, T.; Uhlenbrock, L.; Strube, J. Distinct and Quantitative Validation for Predictive Process Modelling in Steam Distillation of Caraway Fruits and Lavender Flower Following a Quality-By-Design (QbD) Approach. Processes 2020, 8, 594. [CrossRef]

19. Kassing, M.; Jenelten, U.; Schenk, J.; Strube, J. A New Approach for Process Development of Plant-Based Extraction Processes. Chem. Eng. Technol. 2010, 33, 377-387. [CrossRef]

20. Both, S.; Eggersglüß, J.; Lehnberger, A.; Schulz, T.; Schulze, T.; Strube, J. Optimizing Established Processes like Sugar Extraction from Sugar Beets-Design of Experiments versus Physicochemical Modeling. Chem. Eng. Technol. 2013, 36, 2125-2136. [CrossRef]

21. Sixt, M. Entwicklung von Methoden zur Systematischen Gesamtprozessentwicklung und Prozessintensivierung von Extraktions- und Trennprozessen zur Gewinnung pflanzlicher Wertkomponenten; Clausthal University Technology: Clausthal-Zellerfeld, Germany, 2018.

22. Mersmann, A.; Kind, M.; Stichlmair, J. Thermische Verfahrenstechnik. Grundlagen und Methoden, 2nd edition; wesentlich erw. und aktualisierte Aufl; Springer: Berlin, Germany, 2005; ISBN 3-540-23648-1.

23. Sattler, K. Thermische Trennverfahren. Grundlagen, Auslegung, Apparate; VCH Verlagsgesellschaft: Weinheim, Germany, 1988; ISBN 3527267271.

24. Haider, S.; Ashok, A. ICH Harmonised Tripartite Guideline. Biotechnology 2009, 8, 541-655. [CrossRef]

25. ICH Expert Working Group. Riskmanagement (Q9). ICH Harmonised Tripartite Guideline Q9; International Council for Harmonisation of Technical Requirements for Pharmaceuticals for Human Use (ICH): Geneva, Switzerland, 2005.

26. Food and Drug Administration. Guideline for Implimentation of Q9; International Council for Harmonisation of Technical Requirements for Pharmaceuticals for Human Use (ICH): Geneva, Switzerland, 2006.

27. Harnischfeger, G. Bewährte Pflanzendrogen in Wissenschaft und Medizin; Notamed Verl.: Bad Homburg, Germany, 1983; ISBN 3-88907-001-9. 
28. Sixt, M.; Strube, J. Systematic and Model-Assisted Evaluation of Solvent Based- or Pressurized Hot Water Extraction for the Extraction of Artemisinin from Artemisia annua L. Processes 2017, 5, 86. [CrossRef]

29. Schmidt, A.; Sixt, M.; Huter, M.J.; Mestmäcker, F.; Strube, J. Systematic and Model-Assisted Process Design for the Extraction and Purification of Artemisinin from Artemisia annua L.-Part II: Model-Based Design of Agitated and Packed Columns for Multistage Extraction and Scrubbing. Processes 2018, 6, 179. [CrossRef]

30. Mestmäcker, F.; Schmidt, A.; Huter, M.J.; Sixt, M.; Strube, J. Systematic and Model-Assisted Process Design for the Extraction and Purification of Artemisinin from Artemisia annua L.-Part III: Chromatographic Purification. Processes 2018, 6, 180. [CrossRef]

31. Huter, M.J.; Schmidt, A.; Mestmäcker, F.; Sixt, M.; Strube, J. Systematic and Model-Assisted Process Design for the Extraction and Purification of Artemisinin from Artemisia annua L.-Part IV: Crystallization. Processes 2018, 6, 181. [CrossRef]

32. Kaßing, M. Process Development for Plant-Based Extract Production; Shaker: Aachen, Germany, 2012; ISBN 9783844007039.

33. Sixt, M.; Strube, J. Pressurized hot water extraction of 10-deacetylbaccatin III from yew for industrial application. Resour. Technol. 2017, 3, 177-186. [CrossRef]

34. Plaza, M.; Turner, C. Pressurized hot water extraction of bioactives. TrAC Trends Anal. Chem. 2015, 71, 39-54. [CrossRef]

35. Nastić, N.; Švarc-Gajić, J.; Delerue-Matos, C.; Barroso, M.F.; Soares, C.M.; Moreira, M.M.; Morais, S.; Mašković, P.; Srček, V.G.; Slivac, I.; et al. Subcritical water extraction as an environmentally-friendly technique to recover bioactive compounds from traditional Serbian medicinal plants. Ind. Crop. Prod. 2018, 111, 579-589. [CrossRef]

36. F. Hoffmann-La Roche AG. A process for recovering morphine and codeine. CH Patent No. 180189A, Bern, Switzerland, 15 October 1934.

37. Jones, H.E. Method for extraction and purification of thebaine from Papaver beactaetum. LU Patent No. 79165A1, 11 March 1978.

38. Silver, B.S. Subdivided silids extraction method and apparatus. HU Patent No. 222482B1, 28 July 2003.

39. Rogers, L.; Jensen, K.F. Continuous manufacturing-The Green Chemistry promise? Green Chem. 2019, 21, 3481-3498. [CrossRef]

40. Pierre Fabre, S.A. Production of Active Substances. Available online: https://www.pierre-fabre.us/productionactive-substances (accessed on 11 February 2020).

41. McInnis, J.; Tang, Q. Methods and Apparatus for Recovering Zein from Corn. U.S. Patent 6,610,831, 26 August 2003.

42. Harburg-Freudenberger Maschinenbau GmbH. Single Cold Feed Extruders. Available online: https: //www.hf-tiretechgroup.com/en/extrusionstechnologie/extruders/index.html (accessed on 11 February 2020).

43. Freiherr von Bethmann, M.; Lipp, G. Process for extracting substances from plant particles. US Patent No. 3390685A, 2 July 1968.

(C) 2020 by the authors. Licensee MDPI, Basel, Switzerland. This article is an open access article distributed under the terms and conditions of the Creative Commons Attribution (CC BY) license (http://creativecommons.org/licenses/by/4.0/). 